\title{
THAIS CORDESCHI
}

Efetividade de dois intervalos de retorno clinico distintos na incidência de cárie em pré-escolares que apresentaram alto risco de cárie

São Paulo 



\section{THAIS CORDESCHI}

Efetividade de dois intervalos de retorno clinico distintos na incidência de cárie em pré-escolares que apresentaram alto risco de cárie

\section{Versão Corrigida}

Tese apresentada à Faculdade de Odontologia da Universidade de São Paulo, pelo Programa de Pós-Graduação em Ciências Odontológicas para obter o título de Doutor em Ciências.

Área de concentração: Odontopediatria

Orientador: Prof. Dr. Marcelo José Strazzeri Bönecker

São Paulo

2019 
Autorizo a reprodução e divulgação total ou parcial deste trabalho, por qualquer meio convencional ou eletrônico, para fins de estudo e pesquisa, desde que citada a fonte.

Catalogação-na-Publicação

Serviço de Documentação Odontológica

Faculdade de Odontologia da Universidade de São Paulo

Cordeschi, Thais.

Efetividade de dois intervalos de retorno clínico distintos na incidência de cárie em pré-escolares que apresentaram alto risco de cárie / Thais Cordeschi ; orientador Marcelo Bönecker; co-orientador Jenny Abanto -- São Paulo, 2019.

81 p. : fig., tab. ; $30 \mathrm{~cm}$.

Tese (Doutorado) - Programa de Pós-Graduação em Ciências Odontológicas. Área de Concentração: Odontopediatria - Faculdade de Odontologia da Universidade de São Paulo.

Versão corrigida

1. Cárie dentária. 2. Crianças. 3. Ansiedade. I. Bönecker, Marcelo. II. Abanto, Jenny. III. Título. 
Cordeschi T. Efetividade de dois intervalos de retorno clinico distintos na incidência de cárie em pré-escolares que apresentaram alto risco de cárie. Tese apresentada à Faculdade de Odontologia da Universidade de São Paulo para obtenção do título de Doutora em Ciências.

Aprovado em: $08 / 11 / 2019$

\section{Banca Examinadora}

Prof (a). Dr(a). Simone Renó Junqueira Instituição: FOUSP Julgamento: Aprovada

Prof(a). Dr (a). Daniela Hesse Instituição: ACTA Julgamento: Aprovada

Prof (a). Dr (a). Luciana Butini Instituição: São Leopoldo Mandic Julgamento: Aprovada 



\section{AGRADECIMENTOS}

Agradeço primeiramente a Deus, por minha família, meus amigos e as oportunidades que surgiram no meu caminho, e todas as realizações dos sonhos.

A toda a minha família: primos, primas, tios, tias e todos os parentes, de perto e de longe, que influenciaram de alguma forma na minha formação pessoal e profissional. Muito obrigada por todo amor e carinho que sempre me impulsionaram e encorajaram.

Aos meus pais, Maria e Jair, obrigado por todos os momentos dedicados a mim por toda minha vida, pelas palavras, pelos conselhos, pelo amor, pela honestidade, pelo afeto, pela amizade. Vocês me ensinaram a ser forte, a lutar e seguir em frente sem deixar que nenhum obstáculo bloqueasse meu caminho. Espelho-me muito em vocês, pois vocês são o melhor exemplo de ser humano que alguém poderia ter. Muito obrigada por me criar, me educar e me ensinar a viver. Obrigada por aguentar minhas crises de estresse com minhas reclamações, sempre me acalmando e incentivando a seguir em frente! Muito obrigado por tudo o que sacrificaram por mim, para me fazer a pessoa que sou hoje! Sempre serei grata pelo imenso amor e dedicação de vocês. Amo muito vocês.

A minha irmã, Talita, sempre juntas e para sempre. E, mesmo com nossas diferenças, sempre estivemos e estaremos uma perto uma da outra, independentemente de qualquer coisa. Te amo de mais.

A minha irmã e meu cunhado Gabriel por terem me dado um dos maiores presentes que eu já ganhei nessa vida. Minha sobrinha Marina, que tenho o maior orgulho de dizer que também é minha afilhada! Apesar de ter apenas 1 ano e alguns meses é parte tão importante da minha vida, pois ficar perto dela acabou sendo meu lugar preferido, por me trazer a paz que muitas vezes eu preciso.

Ao meu orientador, Professor Marcelo Bönecker, que acreditou em mim desde a época de minha graduação. Obrigada por depositar em mim sua confiança. Obrigada por compartilhar suas ideias, conhecimento e experiências. Sou muito grata por poder ter sido sua orientada, não poderia ter sido melhor. 
À banca examinadora, obrigada por toda atenção e sugestões.

A professora Jenny Abanto, minha co-orientadora. Je, Muito obrigada pelo convívio, pelo apoio, pela compreensão e pela amizade. Muito obrigada por tudo! Você é uma pessoa maravilhosa, guerreira e dedicada! Fico muito feliz pelos anos de companheirismo e sou muito grata por todas as oportunidades que você me dá.

A aluna de iniciação científica Mariana Besseler, Maa... não sei nem por onde começar a te agradecer... dedicada, atenciosa, paciente, amorosa.. e mais outras milhões de qualidades. Nem posso dizer que você foi minha aluna, pois o aprendizado foi mútuo! Quando o desanimo batia ou algo saia do esperado eu só me lembro de você dizendo: "Calma Thata, vai dar tudo certo... NÓs vamos conseguir!". E parabéns, NÓs conseguimos!!! ...E sua voz dizendo essas palavras sempre voltam em meus pensamentos nas horas difíceis. Além de tudo eu ainda ganhei uma amiga! Amo você Ma!

A Gabriela Berti, pelos incentivos constantes e companheirismo em toda a jornada desse estudo.

Aos Professores do Departamento de Odontopediatra. Obrigada pelo exemplo que vocês são! Muito obrigada por todo aprendizado!

Aos funcionários do Departamento de Ortodontia e Odontopediatria, Anne, Júlio, Fátima, Marize e Antônio. Muito obrigada pelo carinho, ajuda, dedicação em tudo! Somos dependentes dos trabalhos de vocês!

A todos os amigos da pós-graduação do departamento de Odontopediatria, por sempre estarem dispostos a ajudar, a compartilhar conhecimentos e principalmente pelas críticas construtivas!

A Bruna Moro, que é minha amiga desde a graduação! Obrigada por me ouvir me aconselhar, me entender! Obrigada pela sua amizade, que é muito importante para mim!

A Nathália, uma das pessoas mais doce que eu conheço, porém ao mesmo tempo, forte, dedicada e inteligente! Obrigada por me ajudar sempre, obrigada por ouvir minas reclamações... Você é muito especial! Um ser humano ímpar, que eu tenho o prazer de dizer que é minha amiga! 
A Manu e Lele, que honra poder trabalhar com vocês!!! Vocês são pessoas maravilhosas... além de companheiras de trabalho, tenho duas amigas que fazem meu dia a dia muito mais leve!! Sei que posso contar com vocês para tudo!

A Gabi Sá... Gabi parabéns por quem você se tornou e onde chegou! Lembro muito de você na graduação e fico muito feliz por todas as suas conquistas!! Obrigada por, mesmo que de maneira indireta, participar desse estudo também!

As minhas amigas da graduação Marianna e Carolina! Minhas melhores lembranças da graduação! Amo vocês!

A minha amiga Stéphanie, Sté nem preciso dizer o quanto amo vc né bestinha... Obrigada por me ouvir, me aconselhar, e por estar sempre presente em absolutamente tudo da minha vida.

As minhas amigas da época de cursinho Bianca, Lívia e Miriane, que se tornaram amigas para a vida toda! Obrigada em especial para a Lívia pelas festas e passeios mais aleatórios e mais engraçados possíveis!

As crianças que fizeram parte dessa pesquisa, e a seus pais! Aos funcionários e diretores das escolas participantes. Muito obrigada pela confiança e acolhimento que tivemos em todas as escolas.

A Fundação de Amparo à Pesquisa do Estado de São Paulo (FAPESP) pela concessão da bolsa de Doutorado (número do processo 2016/13972-9), e reserva técnica que possibilitou a realização desta pesquisa e a minha formação profissional.

A Faculdade de Odontologia da Universidade de São Paulo, desde a graduação. E ao programa de pós-graduação em Ciências, pela oportunidade da realização deste estudo.

... e a todos aqueles que de maneira direta ou indireta contribuíram para a execução desse trabalho.

Muito obrigada! 



\section{RESUMO}

Cordeschi T. Efetividade de dois intervalos de retorno clinico distintos na incidência de cárie em pré-escolares que apresentaram alto risco de cárie. [tese]. São Paulo: Universidade de São Paulo, Faculdade de Odontologia; 2019. Versão Corrigida.

Objetivos: Avaliar a efetividade de dois intervalos de retorno clínico na incidência de cárie (proposição geral) em pré-escolares que apresentaram alto risco de cárie. E avaliar o nível de ansiedade, (proposição específica) de acordo com cada intervalo empregado.

Métodos: A amostra foi composta por 224 crianças de 3 a 5 anos de idade, com alto risco de cárie, de acordo com os critérios da Secretaria Municipal de Saúde de São Paulo. As crianças foram randomizadas em dois grupos: Grupo 1 (G1) - exame clínico bucal + orientação de higiene bucal e dieta com retorno de 4 meses, Grupo 2 (G2) exame clínico bucal + orientação de higiene bucal e dieta com retorno de 8 meses. $O$ nível de ansiedade foi avaliado pela Escala de Imagem Facial, por um dentista externo cego aos grupos de estudo e as características clínicas. O exame clínico bucal foi realizado por um examinador previamente treinado e calibrado, cego aos grupos de estudo. A detecção de lesões de cárie foi feita de acordo com o ICDAS (International Caries Detection and Asessment System). Todos os grupos foram acompanhados durante um período de 30 meses, totalizando sete consultas de retorno para o G1 e três consulta de retorno para o G2. Para as análises foi utilizado um programa estatístico (SPSS), onde o teste de Fischer e Qui-quadrado foram utilizados para avaliar a proporção de crianças com lesões de cárie entre os grupos de estudo no final do estudo, e também para comparar o nível de ansiedade das crianças entre os grupos de estudo no final do estudo. Resultados: A incidência de cárie nas crianças que tiveram retorno a cada 8 meses foi maior do que aquelas que tiveram retorno a cada 4 meses quando comparado os dois grupos no final do estudo $(p=0,033)$. A ansiedade relatada pelas crianças apresentou melhora significantemente maior para o grupo de retorno a cada 4 meses quando comparada ao grupo de retorno a cada 8 meses no final do estudo ( $p=$ 0,027). Conclusão: Os intervalos de retorno a cada 4 meses resultaram em menor incidência de cárie para pré escolares com alto risco de cárie e as crianças pertencentes a esse mesmo grupo apresentaram menores níveis de ansiedade.

Palavras Chaves: Cárie dentária. Crianças. Ansiedade 



\begin{abstract}
Cordeschi T. Effectiveness of two distinct clinical recall intervals in caries incidence in preschool children with high caries risk [thesis]. São Paulo: Universidade de São Paulo, Faculdade de Odontologia; 2019. Versão Corrigida.
\end{abstract}

Objectives: To evaluate the effectiveness of two clinical recall intervals on caries incidence (general proposition) in preschoolers with high caries risk. And evaluate the anxiety level, (specific proposition) according to each interval employed. Methods: The sample consisted of 224 children from 3 to 5 years old, with high caries risk, according to São Paulo Municipal Health Secretariat criteria. The children were randomized into two groups: Group 1 (G1) - oral clinical examination + oral hygiene and diet guidance with recall in 4 months, Group 2 (G2) - oral clinical examination + oral hygiene and diet guidance with recal in 8 months. Anxiety level was assessed by Facial Image Scale, by an external dentist blinded to study groups and clinical characteristics. The clinical oral examination was performed by a previously trained and calibrated examiner, blinded to the study groups. The International Caries Detection and Asessment System (ICDAS) was used for detection of carious lesions. All groups were followed up for a period of 30 months, totaling seven recall visits for $\mathrm{G} 1$ and three recall visits for $\mathrm{G} 2$. For the analyzes we used a statistical program (SPSS), where Fischer and Chi-square tests were used to evaluate the proportion of children with caries lesions between the study groups at the end of the study, and also to compare the level of children's anxiety between study groups at the end of the study. Results: The caries incidence in children who returned every 8 months was higher than those who returned every 4 months when comparing the two groups at the end of the study $(p=0.033)$. The anxiety reported by the children showed a significantly greater improvement for group 1 (recall every 4 months) compared to group 2 every (recall every 8 months) at the end of the study ( $p$ $=0.027)$. Conclusion: Recalls intervals every 4 months for high caries risk preschoolers resulted in a lower caries incidence and also children in this same group had lower levels of anxiety.

Keywords: Dental Caries. Children. Anxiety. 



\section{LISTA DE ABREVIATURAS E SIGLAS}

ECR

EIF

EMEI

ICDAS

TCLE
Ensaio Clínico Randomizado

Escala de Imagem Facial

Escola Municipal de Educação Infantil

International Caries Detection and Asessment System

Termo de consentimento Livre e Esclarecido 

SUMÁRIO

$\begin{array}{ll}\mathbf{1} & \text { INTRODUÇÃO } \\ \mathbf{2} & \text { REVISÃO DE LITERATURA } \\ \mathbf{3} & \text { PROPOSIÇÃO } \\ \mathbf{4} & \text { MATERIAL E MÉTODOS } \\ \mathbf{5} & \text { RESULTADOS } \\ \mathbf{6} & \text { DISCUSSÃO } \\ \mathbf{7} & \text { CONCLUSÕES } \\ & \text { REFERÊNCIAS } \\ & \text { APÊNDICE } \\ & \text { ANEXOS }\end{array}$







\section{INTRODUÇÃO}

A cárie dentária é uma disbiose polimicrobiana causada pela presença de açucar ${ }^{1}$ que possui progressão lenta e caráter dinâmico sendo cumulativa ao longo da vida. As lesões de cárie em desenvolvimento podem ser paralisadas e revertidas em qualquer momento desde que a relação causa-efeito seja modificada ${ }^{2,3}$. Por outro lado, quando há um desequilíbrio no processo de des e re-mineralização dentária, pode haver o desenvolvimento de lesões de cárie ou até mesmo progressão das lesões já existentes ${ }^{4-6}$.

O objetivo das consultas de retorno é manter a saúde bucal da criança tentando evitar o aparecimento de novas lesões de cárie ou progressão de lesões de cárie existentes. Porém poucos estudos avaliam a efetividade desses intervalos de retornos levando em consideração a prevenção da doença cárie, comparando a incidência de cárie entre os intervalos de retorno propostos.

Um dos grandes desafios da Odontopediatria é estabelecer intervalos de retorno preventivos efetivos para crianças que possuem alto risco de cárie. A literatura odontológica não apresenta consenso em relação ao intervalo de tempo ideal para a consulta de retorno para crianças com esse perfil, e esses estão sendo realizados de forma arbitrária, variando entre os países e os sistemas de saúde odontológicos, existindo diversas ferramentas que auxiliam na avaliação do risco e que propõe intervalos de retornos de acordo com o risco ao redor do mundo.

Estudos clínicos randomizados devem ser realizados para melhor compreender qual intervalo de retorno seria mais adequado para manter a saúde bucal de crianças de alto risco de cárie.

Um dos fatores que pode contribuir negativamente para a efetividade dos programas preventivos e intervalos de retorno é a ansiedade que a criança pode apresentar antes da consulta odontológica. A ansiedade odontológica é um problema comum entre crianças e adolescentes ao redor do mundo ${ }^{7}$, além de também ser um fator de risco para a incidência de cárie dentária ${ }^{8}$. Isso ocorre pelo fato de crianças ansiosas serem menos propensas a frequentar o dentista e, portanto, menos expostas a orientações e tratamentos preventivos, sendo essas 
crianças as que apresentam saúde bucal prejudicada ${ }^{9}$. Apesar de o número de visitas de retorno não terem associação com o nível de ansiedade apresentado pelos pacientes ${ }^{10}$, intervalos de retorno mais frequentes podem proporcionar além da melhora da saúde bucal, tratamentos menos invasivos e menores níveis de ansiedade com uma experiência mais positiva durante 0 atendimento odontopediátrico ${ }^{8}$, porém esses dados precisam ser confirmado por ensaios clínicos randomizados, que avaliam o nível de ansiedade de crianças antes da consulta odontológica em diferentes intrvalos de retorno.

O conhecimento sobre a efetividade de consultas odontopediátricas preventivas com retorno regulares pode propiciar a correta distribuição e direcionamento dos recursos econômicos na atenção à saúde bucal de crianças préescolares com alto risco de cárie tanto em ambientes públicos como privados. 


\section{REVISÃO DE LITERATURA}

\subsection{Incidência de Cárie, Avaliação de Risco e Retorno}

A incidência de cárie refere-se às novas lesões que surgem numa determinada população em um determinado intervalo de tempo.

A respeito desse assunto, um estudo epidemiológico realizado no Brasil mostrou uma prevalência de cárie de $53,4 \%$ aos 5 anos de idade ${ }^{11}$.

Controlar essa alta prevalência é um dos grandes desafios da Odontopediatria contemporânea. Vários estudos foram realizados com essa finalidade, por exemplo, um ensaio clínico randomizado em pré-escolares, com diversos níveis de experiência de cárie no baseline, mostrou que, a aplicação semestral de flúor em crianças que escovam os dentes com dentifrício fluoretado e que tem acesso à água de abastecimento público fluoretada, não diminui de forma significativa a incidência de cárie na dentição decídua ${ }^{12}$. Além disso, uma revisão sistemática mostrou que a experiência passada de cárie pode influenciar o desenvolvimento de novas lesões ${ }^{13}$.

Talvez, conhecendo o risco de cárie da criança em desenvolver novas lesões de cárie, possa auxiliar no controle de incidência de cárie, no entanto revisões sistemáticas que avaliaram diversos sistemas/diretrizes, e/ou modelos multivariados isolados de avaliação do risco de cárie, concluíram que a evidência sobre a validade destes sistemas de avaliação é fraca ${ }^{13,14,15}$. Outra revisão sistemática que avaliou a qualidade metodológica dos estudos que mensuram as propriedades das ferramentas de avaliação de risco de cárie para crianças de pouca idade, concluiu que ainda não há evidências suficientes para informar a melhor ferramenta para se avaliar o risco de cárie em crianças ${ }^{16}$. Ou seja, o risco de cárie pode ser uma boa informação para se controlar a incidência de cárie, mas ainda não há métodos confiáveis de avliação de risco de cárie em crianças.

Apesar disso, a Secretaria Municipal da Saúde de São Paulo desenvolveu uma ferramenta ${ }^{17}$, que classifica adultos e crianças de acordo com o risco de cárie e 
determina intervalos de retornos de acordo com o risco. Essa ferramenta foi testada de forma adaptada em um estudo de coorte retrospectivo, com crianças de 1 a 12 anos de idade, e mostrou-se efetiva em termos de prevenção de lesões de cárie ${ }^{18}$. Porém, os autores sugeriram que novos intervalos de retornos fossem testados em ensaios clínicos randomizados, pois os resultados poderiam estar superestimados uma vez que as crianças da amostra faziam parte de um programa preventivo.

Intervalos de retorno também têm sido um assunto muito discutido na Odontopediatria. Apesar de o intervalo de retorno a cada seis meses ter sido usado por muito tempo, uma revisão sistemática concluiu que não há evidência científica que comprove que esse retorno seja efetivo em termos de prevenção de cárie e custos econômicos $^{19}$. Além disso, esta revisão sistemática demonstra que não há evidência suficiente sobre o efeito de se alterar o intervalo de retorno entre as consultas odontológicas.

É interessante observar que durante as últimas décadas, houve uma tendência dos dentistas em estender os intervalo de retorno ${ }^{20}$ muito embora tal conduta possa ter uma forte associação com a alta prevalência de cárie em crianças de cinco anos de idade ${ }^{21}$.

Baseado na literatura, atualmente não há um consenso para determinar intervalos de retornos às consultas odontológicas visando à redução da incidência de cárie em crianças classificadas como alto risco de cárie, tais como apresentando lesões ativas e/ou cavitadas em dentina. 


\subsection{Ansiedade}

Ansiedade odontológica é um tipo de medo a estímulos ameaçadores. Avaliar o nível dessa ansiedade em crianças é muito importante para a realização de um tratamento específico ${ }^{22}$.

Um estudo recente identificou a ansiedade odontológica como um preditor significativo da experiência de cárie, podendo ser um fator de risco para a incidência de cárie dentária ${ }^{23}$, ou seja, crianças que possuem experiências passada de cárie, além de terem maior propensão ao desenvolvimento de novas lesões, podem apresentar níveis mais elevados de ansiedade na consulta. Isso mostra a importância de se avaliar a ansiedade em crianças com alto risco de cárie.

Um outro estudo que avaliou quais fatores poderiam estar associados com medo e a ansiedade pré consulta odontológica para crianças, observou que a ansiedade estava significativamente relacionada aos sintomas dolorosos e experiências negativas de atendimento odontológico anteriores ${ }^{10}$. Interessante notar que o número de visitas à clínica odontológica e tipo de tratamento feito não contribuem para alterar o nível de ansiedade ${ }^{10}$.

Porém não há relatos de ensaios clínicos randomizados que avaliaram a variação da ansiedade em diferentes intervalos de retornos. 





\section{PROPOSIÇÃO}

\subsection{Proposição geral}

- Avaliar a efetividade de dois intervalos de retorno clínico distintos na incidência de cárie em pré-escolares com alto risco de cárie.

\subsection{Proposição específica}

- Avaliar o nível de ansiedade de pré-escolares com alto risco de cárie de acordo com dois intervalos de retornos clínico distintos. 





\section{MATERIAL E MÉTODOS}

O projeto seguiu o delineamento de um Ensaio Clínico Randomizado (ECR) paralelo e foi redigido de acordo com as diretrizes do SPIRIT e CONSORT para ECR's para estudos paralelos ${ }^{24} \mathrm{e}$ as ECR's ${ }^{25}$.

O projeto foi aceito pelo Comitê de Ética da Faculdade de Odontologia da Universidade de São Paulo (FOUSP) com número de parecer 864.405, necessitando posteriormente de emenda, com número do parecer 1.121.868 (ANEXO A), e também foi registrado no ClinicalTrials.gov com protocolo NCT02537184 (ANEXO B).

\subsection{Amostra}

\subsubsection{Cálculo amostral}

O cálculo da amostra foi baseado na prevalência de crianças brasileiras com cárie dentária aos 5 anos de idade que é de $54 \% 17$, poder de $90 \%$ e o nível de significância de $5 \%$ foram usados.

De acordo com o calculo amostral baseado na fórmula de comparação de duas proporções em grupos independentes para o teste qui-quadrado ${ }^{26}, 84$ indivíduos seriam necessários no exame final em cada grupo. No entanto, foi estimada uma perda amostral de $30 \%$, e ao final foi planejado obter pelo menos 110 crianças em cada grupo no início do estudo, compondo uma amostra final de 220 crianças. 


\subsubsection{Seleção da Amostra}

A amostra do presente estudo foi composta por crianças de 3 a 5 anos de idade, de ambos os gêneros, que estavam matriculadas em 5 Escolas Municipais de Educação Infantil (EMEI), que concordaram em participar do estudo, localizadas na região Oeste e Leste da cidade de São Paulo.

Dez diretoras de 10 EMEls foram convidadas para participar do estudo. O projeto de pesquisa foi apresentado para todas as diretoras, porém somente 05 concordaram em participar, sendo 3 da região Oeste e 2 da região Leste.

Nas 05 EMEls onde foi realizado o estudo haviam 721 crianças matriculadas. Todas as escolas participantes do estudo estavam localizadas em regiões que continham abastecimento público de água fluoretada, entre 0,6 e 0,8 ppm de flúor.

Em cada escola que aceitou o convite para participar do estudo, foi realizada uma reunião inicial com as diretoras e coordenadoras com a finalidade de explicar mais detalhadamente o objetivo e a metodologia do estudo.

Foi agendado uma reunião com todos os pais/responsáveis das crianças, as diretoras e professoras, e a equipe de pesquisa. Durante essa reunião foi possível esclarecer aos pais/responsáveis os objetivos e etapas metodológicas do estudo. Todas as dúvidas que surgiram foram esclarecidas. Nesse mesmo dia foi feito orientações de saúde bucal para os pais, onde foram abordados temas como: dentifrício fluoretado, quantidade de dentifrício na escova de acordo com a idade, escovação, importância da escovação noturna, erupção dos dentes permanentes, uso do fio dental e dieta cariogênica. Ao final da reunião, todos os responsáveis que aceitaram que seus filhos participassem da pesquisa assinaram os termos de consentimento livre e esclarecido (TCLE) (APÊNDICE A). 


\subsection{Critérios de inclusão e exclusão}

\subsubsection{Critérios de inclusão:}

- Crianças com alto risco de cárie, de acordo com os critérios clínicos da Secretaria Municipal de Saúde de São Paulo $(2012)^{17}$, ou seja, essas crianças deveriam apresentar clinicamente lesões de cárie ativa cavitadas ou não cavitadas.

- Crianças de 3 a 5 anos de idade, que morassem em São Paulo ou região há pelo menos 1 ano, cujos responsáveis estavam planejando a permanência na cidade por no mínimo os três anos seguintes a data inicial da primeira avaliação da criança no estudo e que possuíssem endereço fixo e telefone, ou ter um parente próximo que possuísse telefone.

- Crianças cujo responsável assinasse o termo de consentimento livre e esclarecido (TCLE).

\subsubsection{Critérios de exclusão:}

- Crianças que se alimentassem via sonda

- Crianças com deficiência cognitiva e/ou motora

- Crianças que recebiam medicação de uso crônico em forma de xaropes

- Crianças portadoras de aparelho ortodôntico fixo e/ou que apresentassem anomalias de desenvolvimento dentário.

- Crianças que tinham recebido aplicação profissional de flúor em consultório nos 6 meses anteriores ao estudo.

- Crianças que apresentassem fístula, dor ou abscesso dental com necessidade de terapia pulpar e/ou extração dentária. 


\subsection{Treinamento e Calibração}

Os exames clínicos desse estudo foram realizados por uma examinadora previamente treinada por um expert.

O treinamento englobou duas aulas teóricas e duas aulas práticas com dez crianças que não fizeram parte da amostra. E foi realizado para a utilização do índice de placa dentária de Greene e Vermillion simplificado (1964) ${ }^{27}$, índice de sangramento gengival de Löe $(1967)^{28}$, e detecção das lesões de cárie por International Caries Detection and Assessment System - ICDAS ${ }^{29}$, associado com o critério para avaliar atividade baseada nas características das lesões descritas previamente no manual publicado pelo comitê do ICDAS (ANEXO C).

As avaliações do desfecho secundário foram realizadas pelo entrevistador externo (MB) previamente treinado por um expert em relação à leitura e entonação de voz para a correta realização do questionário de ansiedade por meio da Escala de Imagem Facial (EIF).

Para a calibração dos escores do Índice de Greene e Vermillion simplificado (ANEXO D), fotografias dos dentes evidenciados de oito crianças foram apresentadas.

Para a calibração os escores do Índice de Löe (1967) (ANEXO E) ${ }^{28}$, filmes mostrando a sondagem completa dos dentes, também de oito crianças, foram apresentados para a examinadora como a determinação do índice.

Para a calibração dos critérios e escores do ICDAS a examinadora avaliou 30 imagens e 10 superfícies de dentes do Banco de Dentes englobando todos os escores do ICDAS e deu o devido escore.

Após uma semana, as mesmas imagens dos Índices de Greene Vermillion e Löe foram avaliados novamente, assim como as mesmas 10 superfícies dos dentes utilizados para a calibração do ICDAS. A reprodutibilidade intra-examinador dos índices foi obtida através da comparação dos resultados da examinadora obtidos no primeiro dia de análise e após uma semana, foi calculada pelo teste de Kappa, que 
apresentou valores de 0,89 para os Índices de Greene Vermillion e Löe, e 0,78, para o ICDAS.

Foi feita a concordância interexaminador com as mesmas imagens dos Índices de Greene Vermillion e Löe, assim como as mesmas 10 superfícies dos dentes utilizados para a calibração do ICDAS. As taxas de concordância positiva e negativa de $90 \%$, apresentou um valor de porcentagem geral de concordância de $90 \%$, Kappa $=0,87$ e um intervalo de confiança de $95 \%(0,65-0,95)$.

\subsection{Identificação do paciente e dados socioeconômicos}

Para a identificação das crianças foram coletados com os pais no dia da assinatura do TCLE dados como nome da criança e telefone para contato. Posteriormente por telefone, para as crianças que foram incluídas no estudo foram feitas a confirmação do nome, sexo, idade, e foi coletado o endereço residencial.

As condições socioeconômicas também foram coletadas por telefone, como: número de irmãos, o grau de escolaridade dos pais, estrutura familiar (família nuclear - pai e mãe e família não nuclear - mãe e companheiro, pai e companheira ou outros) e renda familiar mensal.

\subsection{Avaliação Inicial}

A avaliação inicial foi realizada na unidade escolar na qual a criança encontrava-se. Das 721 crianças matriculadas nas 05 escolas participantes, somente 65 pais não assinaram o TCLE.

As 656 crianças que tinham o TCLE assinado pelos pais/responsáveis foram convidadas para a avaliação inicial. Uma criança de cada vez era convidada a se dirigir a uma sala especifica na escola onde estavam a pesquisadora e um entrevistador externo. 
Antes de a criança entrar na sala de exame clínico, a mensuração do nível de ansiedade da criança foi realizada por um entrevistador externo (GOB).

\subsubsection{Ansiedade da criança}

O nível de ansiedade foi avaliado por meio da Escala de Imagem Facial $(E I F)^{30}$ (ANEXO F), sendo que de acordo com os protocolos de aplicação, cada criança foi abordada fora da sala de atendimento ${ }^{30}$, pelo entrevistador externo treinado, antes do início da avalição inicial e das consultas de retorno. As crianças foram convidadas a apontar para o rosto que elas sentissem que mais representava seus sentimentos no momento precedente a consulta odontológica.

\subsubsection{Exame clínico}

Após a mensuração da ansiedade, as 656 crianças foram então submetidas a um exame clínico inicial sequencial pelo examinador (TC). O exame clínico foi realizado em uma sala da escola, bem iluminada com luz natural, utilizando-se luz de um refletor, e com a criança na posição horizontal sobre uma mesa e um colchão para melhor conforto da criança.

\section{A) Detecção de placa visível}

A detecção de placa visível foi feita através da identificação de biofilme evidente a olho nu. Caso a criança apresenta-se placa visível em qualquer superfície dental era anotado na ficha do paciente como: - com placa visível ou - sem placa visível. 


\section{B) Índice de sangramento}

Foi realizado o índice de sangramento de $L o ̈ e^{28}$, com o auxílio de uma sonda periodontal. A sonda de ponta romba foi passada gentilmente nas superfícies vestibulares e linguais de 6 dentes decíduos: 55 (vestibular), 65 (vestibular), 61 (vestibular), 81 (vestibular), 75 (lingual) e 85 (lingual). Os escores foram registrados: $0=$ sem sangramento; 1 = edema; 2 = sangramento à sondagem; 3 = sangramento espontâneo. $O$ índice no final foi calculado somando todos os escores e dividindo este valor pelo número de dentes avaliados. Sendo que os índices finais quantitativos foram transformados para qualitativos da seguinte maneira: $0,1-1$ : gengivite leve; 1,1-2: gengivite moderada; 2,1-3: gengivite severa.

\section{C) Índice de Placa corada}

Foi realizada evidenciação de biofilme dentário com verde de malaquita e os dentes foram avaliados de acordo com os critérios do índice de Greene e Vermillion simplificado $(1964)^{27}$. O índice considera os mesmos dentes e superfícies do Índice de sangramento de $\mathrm{Löe}^{28}$, portanto foram corados somente as superfícies necessárias. Os escores foram registrados: $0=$ sem placa; $1=$ até $1 / 3$ da superfície com placa; 2 = entre $1 / 3$ e $2 / 3$ da superfície com placa; 3 = mais de $2 / 3$ da superfície com placa. O índice final foi calculado da mesma maneira que o Índice de sangramento de $\mathrm{Löe}^{28}$, sendo atribuídos também dados quantitativos e qualitativos aos escores dos índices finais da seguinte maneira: Bom = 0,0 - 1,0; Regular $=1,1-$ 2,0; Ruim = 2,1-3,0.

\section{D) Orientação de higiene e escovação}

Após a evidenciação de placa, todas as crianças receberam orientações de higiene bucal como: dieta, importância da escovação noturna, quantidade de creme dental na escova e foi ensinada escovação seguindo a técnica de Fones. A Técnica de Fones foi escolhida por ser simples e não requerer muita habilidade na sua realização ${ }^{31}$. As instruções de higiene bucal foram dadas com auxílio de macromodelos, sempre pelo mesmo dentista externo. Visto que os primeiros molares 
permanentes de algumas crianças econtravam em fase de erupção, durante esse período, os pais e as crianças foram orientados a usar uma técnica de escovação especial designada para estes dentes em erupção ${ }^{32}$.

Após as orientações, as crianças foram levadas até uma pia com espelho para que realizassem a escovação supervisionada por um profissional. Mesmo considerando a profilaxia dental como um recurso auxiliar para a remoção de biofilme dentro do consultório odontológico, a profilaxia dental prévia à avaliação das superfícies dentárias, principalmente de lesões iniciais e da sua atividade, tem sido preconizada $^{33,34}$. Portanto, antes da avaliação era realizada a escovação profissional.

Um kit de higiene bucal contendo uma escova infantil e um dentifrício fluoretado de 1,450 ppm de monofluorfostato de sódio (Colgate Máxima Proteção Anticáries; Colgate-Palmolive, Brasil) foi entregue para todas as crianças.

Durante o período de estudo, o uso de dentifrício fluoretado contendo 1,450 ppm de monofluorfostato de sódio foi recomendado e enfatizado para todas as crianças, com quantidade equivalente a um grão de ervilha ${ }^{12}$. Também foi orientado o uso de fio dental supervisionado pelos pais.

\section{D) Detecção de lesões de cárie}

Após a escovação profissional as crianças retornaram a sala de atendimento e foi feito exame clínico para a detecção das lesões de cárie, utilizando o índice ICDAS ${ }^{29}$. O ICDAS avalia a severidade, definindo a presença ou não de cavidades, e estimando a profundidade das lesões.

Foi feito o exame visual de todas as superfícies da dentição decídua completa, previamente limpas, e secas com rolete de algodão e, eventualmente, dos primeiros molares permanentes em erupção, sempre pelo mesmo examinador cego aos grupos de estudo.

A examinadora contou com o auxílio de uma sonda tipo OMS (Ball point), para a sondagem das superfícies e detecção de possíveis rugosidades, cavidades ou perda da continuidade do esmalte. 
Nesse momento era feita a avaliação de risco de cada criança, sendo que crianças com lesões ativas eram consideradas pacientes de alto risco de cárie. Essas crianças foram mantidas nessa classificação até o final do estudo, pois a experiência passada de cárie é o fator preditivo mais poderoso para o desenvolvimento de novas lesões ${ }^{13}$.

\section{E) Tratamento das lesões}

Durante a avaliação inicial, as crianças que apresentaram superfícies com lesões de carie cavitadas receberam tratamento odontológico operatório por meio da técnica de $\mathrm{ART}^{35}$ onde foi utilizado cimento ionômero de vidro de alta viscosidade. $\mathrm{O}$ mesmo procedimento foi realizado quando foram diagnosticadas novas lesões de carie cavitadas nas consultas de retorno.

Todas as crianças que apresentavam lesões ativas receberam aplicação tópica profissional de flúor verniz (Duraphat, Colgate Oral Pharmaceuticals, New York, N.Y., USA) na dentição completa. Uma porção pequena de verniz ${ }^{10}$ foi utilizada para cada criança. Após o isolamento relativo, os dentes foram secos com rolete de algodão e o verniz foi aplicado em toda a dentição com um microbrush descartável. Os professores da escola foram orientados a não fornecer as crianças alimentos duros e a não escovar os dentes das crianças no dia da aplicação do verniz ${ }^{12}$.

Todos os procedimentos realizados em cada criança foram descritos para os pais por meio da agenda escolar.

\section{F) Orientação de saúde bucal e dieta}

A orientação de saúde bucal para os pais foi reforçada a cada seis meses nas reuniões de pais e mestres de cada escola. Nessas orientações foram abordados temas como: dentifrício fluoretado, quantidade de dentifrício na escova de acordo com a idade, escovação, importância da escovação noturna, erupção dos dentes permanentes, fio dental e dieta cariogênica. 


\subsection{Randomização e cegamento dos grupos}

Após as etapas descritas acima, pode-se observar que 432 crianças não preencheram os critérios de inclusão do estudo. As razões pelas quais as crianças não foram incluídas foram as seguintes: 249 crianças possuiam risco baixo e moderado ${ }^{17}, 6$ crianças tinham deficiências cognitivas e / ou motoras, 17 usavam medicação crônica em forma de xarope, 12 tinham aparelhos ortodônticos fixos, 24 tinham anomalias dentárias, 38 tinham aplicação profissional de flúor nos últimos 6 meses, 86 apresentavam fístula, dor ou abscesso dentário. Completando a amostra final de 224 crianças (Figura 4.2).

As crianças que fizeram parte da amostra $(n=224)$ foram randomizados em dois grupos de estudo levando em consideração lesões cavitadas em dentina, pois a experiência passada de cárie pode influenciar o desenvolvimento de novas lesões ${ }^{14}$, portanto a gravidade das lesões de cárie poderia ser um fator de confusão e influenciar os resultados.

Foi feita uma divisão entre pacientes com e sem lesões em dentina e um pesquisador externo $(\mathrm{JA})$ alocou as crianças de maneira igual nos grupos do estudo utilizando um gerador de números randômicos online de maneira que os dois grupos de retorno possuíssem crianças com características semelhantes.

O examinador (TC) realizou as avaliações clínicas bucais e foi cego a alocação e aos desfechos secundários, realizados pelo dentista externo (GOB).

\subsection{Grupos de estudo}

As crianças foram randomizadas em dois grupos de estudo, onde os intervalos de retorno eram de 4 e 8 meses, uma vez que o modelo proposto pela Secretaria de Saúde da cidade de São Paulo sugere que pacientes com alto risco de 
cárie tenham intervalos de retorno a cada 8 meses para pacientes com lesões ativas não cavitadas e 4 meses para pacientes com lesões cavitadas em dentina ${ }^{17}$.

- Grupo 1 (G1) - Intervalo de retorno a cada 4 meses.

- Grupo 2 (G2) - Intervalo de retorno a cada 8 meses. 


Figura 2: Fluxograma

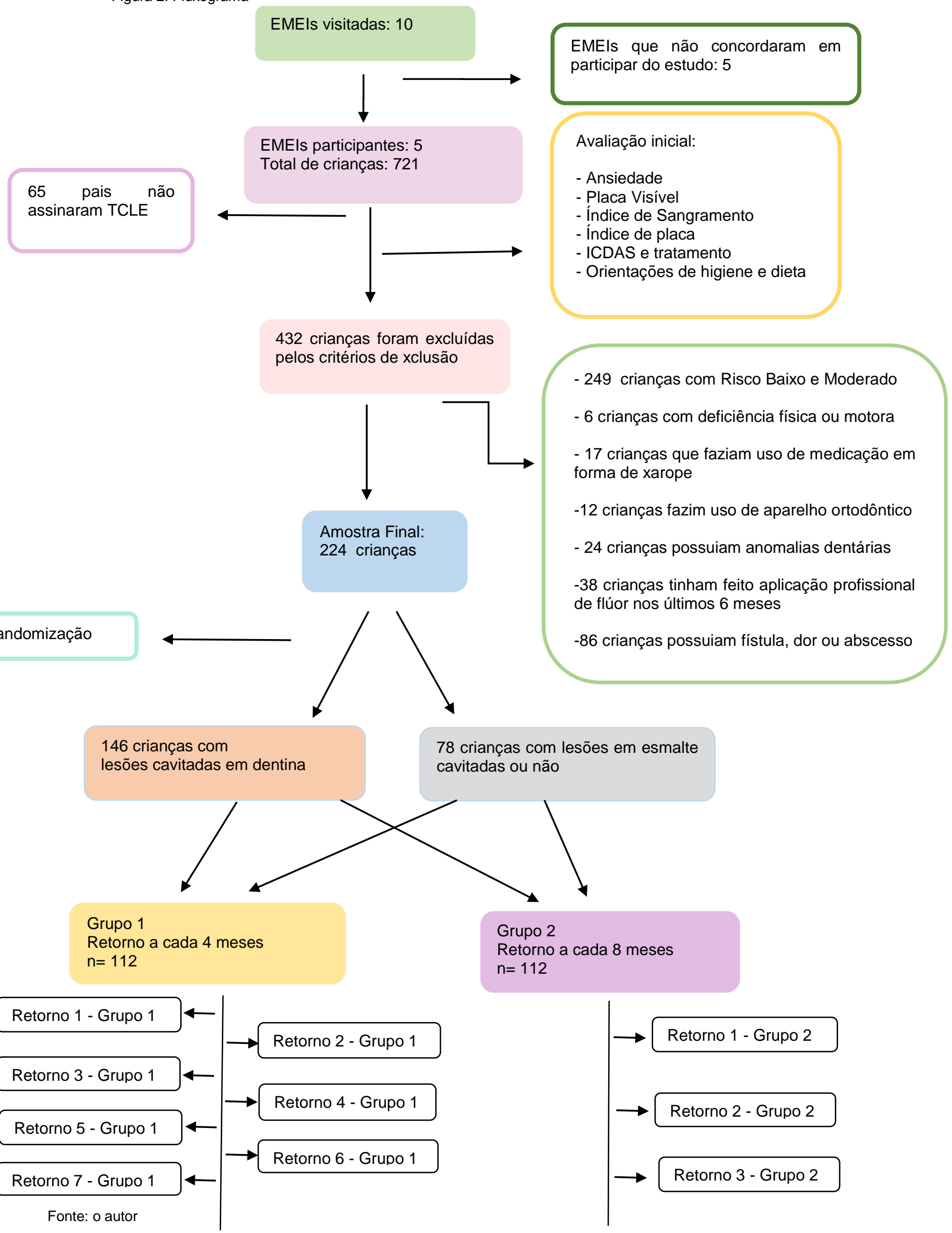




\subsection{Consultas de retorno}

Os dois grupos foram acompanhados durante um período de 30 meses, totalizando sete consultas para o G1 (intervalo de 4 meses), e três consultas de retorno para o G2 (intervalo de 8 meses). Todos os procedimentos descritos do item 4.5.1 (Ansiedade) e 4.5.2 (Exame clínico) foram realizados em todos os retornos para os dois grupos de estudo. Em relação ao tratamento descrito no item 4.5.2. E) somente foi realizado o tratamento operatório em crianças que apresentaram lesões cavitadas em dentina ao longo do estudo.

Caso alguma criança desenvolvesse, durante o período do estudo, alguma lesão que não era possível ser tratada no ambiente escolar, a mesma era encaminhada para receber tratamento na Faculdade de Odontologia da Universidade de São Paulo (FOUSP). Caso a criança não pudesse comparecer à Fousp, era feito um encaminhamento para tratamento na Unidade Básica de Saúde mais próxima.

Como descrito anteriormente, todos os grupos receberam em cada consulta de retorno um kit de higiene bucal contendo uma escova infantil e um dentifrício fluoretado de 1,450ppm de monofluorfostato de sódio (Colgate Máxima Proteção Anticáries; Colgate-Palmolive, Brasil).

Após a realização de todas as consultas de retorno em ambos os grupos os pais recebiam ligações para serem reforçadas as orientações de prevenção, já que os pais não estavam presentes durante o atendimento de cada criança. 


\subsection{Análises estatísticas}

Para todas as análises foi utilizado o programa estatístico Statistical Package for the Social Sciences (SPSS for Windows, version 19.0, Chicago, IL, USA). Cada teste de hipótese foi bicaudal, adotando-se um nível de significância de 5\% para todas as análises. A reprodutibilidade intra-examinador para a cárie dentária pelo critério do ICDAS a nível de superfície de dente foi mensurada pelo coeficiente de Kappa.

Análises descritivas foram realizadas para resumir as características clínicas de sócio demográficas de cada grupo de estudo na avaliação inicial com o intuito de avaliar quão comparáveis foram os grupos no início do estudo. Um total de 16 parâmetros (por exemplo, sexo, idade, etc.) foram incluídos nas análises. Para os grupos de retorno a classificação foi feita da seguinte forma: Grupo de retorno (1. G1 - 4 meses ou 2. G2 - 8 meses).

Para as análises das variáveis sociodemográficas, foram classificadas da seguinte forma: Gênero (1. Feminino ou 2. Masculino). Idade (3, 4 ou 5). Vive com (1. mãe e pai, 2.Outros). Renda (1. Menos que três salários mínimos ou 2. 3 ou mais salários mínimos). Irmãos (1. não irmãos ou 2.sim irmãos). Escolaridade da mãe (1. menos de 8 anos ou 2.mais de 8 anos). Escolaridade do Pai (1. menos de 8 anos ou 2.mais de 8 anos).

Para as condições clínicas, as variáveis foram classificadas da seguinte forma: Placa visível (1. nenhuma placa visível ou 2. sim placa visível). Sangramento gengival (1.Não ou 2.Sim). Placa corada (1.No Placa, 2.Bom ou 3.Regular / Ruim). Crianças com lesões iniciais (1.Não ou 2.Sim). Crianças com lesões moderadas (1.Não ou 2.Sim). Crianças com lesões severas (1.Não ou 2.Sim). 
4.9.1 Incidência de cárie

A incidência de cárie foi dividida em três pontos de corte: lesões iniciais mancha branca (ICDAS 1 e 2), lesões moderadas - em esmalte (ICDAS 3 e 4) e lesões severas - cavitadas em dentina (ICDAS 5 e 6), sempre considerando o pior score do ICDAS apresentado pela criança. Além disso, os pacientes foram classificados de acordo com a quantidade de lesões apresentadas dentro dos pontos de corte (0 lesões, 1 lesão ou > 2 lesões). Os testes de Fisher e Quiquadrado foram usados para avaliar a proporção de crianças com lesões de cárie entre os grupos do estudo na avaliação inicial e para comparar os grupos do estudo nos intervalos de retorno. O teste exato de Fisher e o teste do qui-quadrado foram usados também para análises comparando os dois grupos no final do estudo para todos os desfechos.

\subsubsection{Ansiedade}

O nível de ansiedade mensurado pela EIF tem escores de intervalo estreito (1-5) e a categorização foi feita da seguinte forma: 1. Muito feliz e Feliz; 2. Normal; 3. Triste e Muito Triste.

Após as categorizações foram utilizados os testes Exato de Fisher e Quiquadrado para comparar as respostas das crianças entre a avaliação inicial e a avaliação final e os grupos no final do estudo, após 30 meses de acompanhamento. 


\section{RESUltados}

Durante a realização do presente estudo, uma examinadora previamente treinada e calibrada realizou todas as avaliações clínicas (TC). A reprodutibilidade intra-examinador para avaliação clínica das lesões de cárie utilizando os critérios do ICDAS foi de 0,78 . O valor de Kappa para a avaliação da reprodutibilidade intraexaminador dos índices de Greene e Vermillion simplificado e Löe foram superiores a 0,89 .

O total da amostra foi de 224 crianças sendo 112 crianças para cada grupo de estudo (G1 e G2). Das 224 crianças incluídas e que foram randomizadas no início do estudo, 165 crianças permaneceram até o final do estudo (taxa de perda amostral = 26,33\%), correspondendo ao $G 1 \quad(n=81)$, e ao $G 2(n=84)$. As razões para as perdas foram: 2 crianças foram diagnosticados durante o estudo com alterações psicomotoras, 3 crianças mudaram de cidade, 2 crianças os pais não quiseram mais fazer parte do estudo. As demais crianças mudaram de escola dificultando assim para a equipe de pesquisa em fazer os exames clínicos ou entrar em contato com os familiares das crianças.

As tabelas 5.1 .1 e 5.1 .2 caracterizam as condições das 224 crianças no começo do estudo e as tabelas 3 e 4 são referentes aos resultados encontrados para os objetivos estabelecidos levando em consideração somente as 165 crianças que permaneceram no estudo por 30 meses.

Os dados coletados na avaliação final são referentes a condições clinicas em que as crianças se apresentavam no momento dos exames clínicos feitos, e não levou em consideração os acontecimentos que ocorreram durante o tratamento. 


\subsection{Avaliação das condições sociodemográficas e clínicas das crianças na avaliação inicial}

A Tabela 5.1 apresenta as características das crianças nos dois grupos de estudo (G1 e G2).

Em relação aos dados sociodemográficos, podemos observar que a amostra foi composta por $50,8 \%$ do sexo feminino, sendo que $70,5 \%$ das crianças moravam com pai e mãe, $63,8 \%$ possuíam renda inferior a 3 salários mínimos, $63,8 \%$ tinham um ou mais irmãos, $73,2 \%$ das mães das crianças possuíam escolaridade inferior á 8 anos, e 72,3\% dos pais com escolaridade inferior á 8 anos. Observa-se que maioria das famílias era composta por núcleo familiar completo com pai e mãe com 2 filhos ou mais e apresentavam baixa renda e baixo nível de escolaridade. A maioria das variáveis sobre dados socioedemográficos não foram estatisticamente diferentes entre os grupos de estudo.

Para os dados clínicos, observou-se que $81,2 \%$ das crianças possuíam placa visível, $64,7 \%$ sangramento gengival, $82,6 \%$ placa corada entre regular e ruim, $60 \%$ tinham lesões iniciais $63,8 \%$ lesões moderadas e $34,8 \%$ apresentavam lesões severas. Observa-se que a maioria das crianças apresentava saúde bucal critica. A maioria das variáveis sobre dados clínicos não foram estatisticamente diferentes entre os grupos de estudo.

De acordo com os critérios de inclusão estabelecidos, todas as 224 crianças da amostra teriam que apresentar algum tipo de lesão de cárie ativa, seja em esmalte ou dentina. Para realizar a randomização das crianças por grupo, o principal critério clinico levado em consideração foi a presença de lesão de cárie em dentina, por isso as crianças que apresentavam ao menos uma lesão de cárie em dentina foram igualmente distribuídas entre os G1 e G2, por isso observa-se na tabela 1 o valor de $\mathrm{p}=1$ para essa variável.

Não houve diferença estatística para os dados clínicos e sociodemográficos entre os grupos de estudo. 
Tabela 5.1 - Número e porcentagem de crianças com alto risco de cárie de acordo com os intervalos de retorno e segundo variáveis sociodemográficas e clínicas ao inicio do estudo

\begin{tabular}{|c|c|c|c|c|c|c|}
\hline \multirow[b]{3}{*}{ Variáveis } & \multirow[b]{3}{*}{ Categorização } & \multicolumn{4}{|c|}{ Intervalos de Retorno } & \multirow[b]{3}{*}{$\mathbf{P}$} \\
\hline & & \multicolumn{2}{|c|}{ G1 - 4 meses } & \multicolumn{2}{|c|}{ G2 - 8 meses } & \\
\hline & & $\mathbf{N}$ & $\%$ & $\mathbf{N}$ & $\%$ & \\
\hline \multirow{2}{*}{ Sexo } & Feminino & 50 & $44,6 \%$ & 64 & $57,1 \%$ & 0,061 \\
\hline & Mascuino & 62 & $55,4 \%$ & 48 & $42,9 \%$ & df 1 \\
\hline \multirow{3}{*}{ Idade } & 3 & 24 & $21,4 \%$ & 19 & $17,0 \%$ & 0,451 \\
\hline & 4 & 45 & $40,2 \%$ & 54 & $48,2 \%$ & df 2 \\
\hline & 5 & 43 & $38,4 \%$ & 39 & $34,8 \%$ & \\
\hline \multirow{2}{*}{ Mora com } & Mãe e pai & 81 & $72,3 \%$ & 77 & $68,8 \%$ & 0,558 \\
\hline & Outros & 31 & $27,7 \%$ & 35 & $31,3 \%$ & df 1 \\
\hline \multirow{2}{*}{ Renda } & $\begin{array}{l}3 \text { salários } \\
\text { mínimos }\end{array}$ & 86 & $76,8 \%$ & 57 & $50,9 \%$ & $>0,001$ \\
\hline & $\begin{array}{l}<3 \text { salários } \\
\text { mínimos }\end{array}$ & 26 & $23,2 \%$ & 55 & $49,1 \%$ & df 1 \\
\hline \multirow{2}{*}{ N. de irmãos } & Sem irmãos & 38 & $33,9 \%$ & 43 & $38,4 \%$ & 0,487 \\
\hline & Com irmãos & 74 & $66,1 \%$ & 69 & $61,6 \%$ & df 1 \\
\hline \multirow{2}{*}{ Escolaridade da mãe } & $<8$ anos & 32 & $28,6 \%$ & 28 & $25,0 \%$ & 0,546 \\
\hline & $>8$ anos & 80 & $71,4 \%$ & 84 & $75,0 \%$ & df 1 \\
\hline \multirow{2}{*}{ Escolaridade do pai } & $<8$ anos & 43 & $38,4 \%$ & 19 & $17,0 \%$ & $>0,001$ \\
\hline & $>8$ anos & 69 & $61,6 \%$ & 93 & $83,0 \%$ & df 1 \\
\hline \multirow{2}{*}{ Placa Visível } & Sem placa & 90 & $80,4 \%$ & 92 & $82,1 \%$ & 0,732 \\
\hline & Com placa & 22 & $19,6 \%$ & 20 & $17,9 \%$ & df 1 \\
\hline \multirow{2}{*}{ Sangramento gengival } & Não & 71 & $63,4 \%$ & 74 & $66,1 \%$ & 0,675 \\
\hline & Sim & 41 & $36,6 \%$ & 38 & $33,9 \%$ & df 1 \\
\hline \multirow{2}{*}{ Placa Corada } & Sem Placa/Bom & 20 & $17,9 \%$ & 19 & $17,0 \%$ & 0,860 \\
\hline & Regular/Ruim & 92 & $82,1 \%$ & 93 & $83,0 \%$ & df 1 \\
\hline \multirow{2}{*}{$\begin{array}{l}\text { Crianças com } \\
\text { lesões iniciais }\end{array}$} & Não & 43 & $38,4 \%$ & 47 & $42,0 \%$ & 0,586 \\
\hline & Sim & 69 & $61,6 \%$ & 65 & $58,0 \%$ & \\
\hline \multirow{2}{*}{$\begin{array}{l}\text { Crianças com } \\
\text { lesões moderadas }\end{array}$} & Não & 31 & $27,7 \%$ & 50 & $44,6 \%$ & 0,008 \\
\hline & Sim & 81 & $72,3 \%$ & 62 & $55,4 \%$ & df 1 \\
\hline \multirow{2}{*}{$\begin{array}{l}\text { Crianças com } \\
\text { lesões severas }\end{array}$} & Não & 73 & $65,2 \%$ & 73 & $65,2 \%$ & 1 \\
\hline & Sim & 39 & $34,8 \%$ & 39 & $34,8 \%$ & df 1 \\
\hline Total & & 112 & & 112 & & \\
\hline
\end{tabular}

Fonte: O autor 
A tabela 5.2 apresenta as características de crianças que permaneceram e que foram perdidas no decorrer do estudo de acordo com dados sociodemográficos e clínicos. Para essas análises foram avaliadas para cada variável e sua categorização as proporções do número de crianças perdidas no decorrer do estudo em relação ao número de crianças que permaneceram até o final do estudo.

Os próprios grupos de estudo aparecem como uma das variáveis nessa análise. Observa-se que 31 crianças foram perdidas no G1 e 28 crianças foram perdidas no G2. Partindo do princípio que ambos os grupos começaram o estudo com 112 crianças, podemos observar que as proporções entre as crianças perdidas e as que permaneceram em cada grupo de estudo, foram similares nos dois grupos, não havendo assim diferença estatística entre eles $(p=0,649)$. O número de crianças perdidas no decorrer do estudo poderia ter sido, muito maior ou exclusiva a um único grupo de estudo, mas isso não ocorreu, mostrando que mesmo com as perdas os grupos G1 e G2 ainda apresentavam -se proporcionais em relação à amostra.

Somente para lesões severas a proporção do número de crianças perdidas apresentou diferença significativa com o número de crianças que permaneceu no estudo ( $p=0,003$ ). Porém estavam igualmente distribuídas nos dois grupos.

O número de crianças que permaneceu no estudo não difere significantemente daquelas perdidas nas consultas de retorno para a maioria das variáveis, podemos assim avaliar a efetividade dos intervalos de retorno com a amostra final $(n=165)$. 
Tabela 5.2 - Número total e porcentagem de crianças com alto risco de cárie ao final do estudo e perdidas durante o estudo segundo variáveis sociodemográficas e clínicas

\begin{tabular}{|c|c|c|c|c|c|c|}
\hline \multirow[b]{2}{*}{ Variáveis } & \multirow[b]{2}{*}{ Categorização } & \multicolumn{2}{|c|}{$\begin{array}{l}\text { Total de crianças ao } \\
\text { final do estudo } \\
\text { G1 e G2 }\end{array}$} & \multicolumn{2}{|c|}{$\begin{array}{l}\text { Total de crianças } \\
\text { perdidas durante o } \\
\text { estudo } \\
\text { G1 e G2 }\end{array}$} & \multirow[b]{2}{*}{ p Valor } \\
\hline & & $\mathbf{N}$ & $\%$ & $\mathbf{N}$ & $\%$ & \\
\hline \multirow{2}{*}{ Grupo } & 4 meses & 81 & $49,1 \%$ & 31 & $52,5 \%$ & 0,649 \\
\hline & 8 meses & 84 & $50,9 \%$ & 28 & $47,5 \%$ & \\
\hline \multirow{2}{*}{ Sexo } & feminino & 88 & $53,3 \%$ & 26 & $44,1 \%$ & 0,222 \\
\hline & masculino & 77 & $46,7 \%$ & 33 & $55,9 \%$ & \\
\hline \multirow{3}{*}{ Idade } & 3 & 34 & $20,6 \%$ & 9 & $15,3 \%$ & 0,226 \\
\hline & 4 & 76 & $46,1 \%$ & 23 & $39,0 \%$ & \\
\hline & 5 & 55 & $33,3 \%$ & 27 & $45,8 \%$ & \\
\hline \multirow{2}{*}{ Mora com } & Mãe e pai & 115 & $69,7 \%$ & 43 & $72,9 \%$ & 0,645 \\
\hline & outros & 50 & $30,3 \%$ & 16 & $27,1 \%$ & \\
\hline \multirow{2}{*}{ Renda } & < 3 salários mínimos & 100 & $60,6 \%$ & 43 & $72,9 \%$ & 0,092 \\
\hline & >3 salários mínimos & 65 & $39,4 \%$ & 16 & $27,1 \%$ & \\
\hline \multirow{2}{*}{ Irmãos } & Sem irmãos & 62 & $37,6 \%$ & 19 & $32,2 \%$ & 0,461 \\
\hline & Com irmãos & 103 & $62,4 \%$ & 40 & $67,8 \%$ & \\
\hline \multirow{2}{*}{$\begin{array}{l}\text { Escolaridade da } \\
\text { mãe }\end{array}$} & $<8$ anos & 43 & $26,1 \%$ & 17 & $28,8 \%$ & 0,682 \\
\hline & $>8$ anos & 122 & $73,9 \%$ & 42 & $71,2 \%$ & \\
\hline \multirow{2}{*}{ Escolaridade do pai } & $<8$ anos & 44 & $26,7 \%$ & 18 & $30,5 \%$ & 0,571 \\
\hline & $>8$ anos & 121 & $73,3 \%$ & 41 & $69,5 \%$ & \\
\hline \multirow{2}{*}{ Placa visível } & Sem placa visível & 131 & $79,4 \%$ & 51 & $86,4 \%$ & 0,234 \\
\hline & Com placa visível & 34 & $20,6 \%$ & 8 & $13,6 \%$ & \\
\hline \multirow{2}{*}{$\begin{array}{l}\text { Sangramento } \\
\text { gengival }\end{array}$} & Não & 106 & $64,2 \%$ & 39 & $66,1 \%$ & 0,798 \\
\hline & Sim & 59 & $35,8 \%$ & 20 & $33,9 \%$ & \\
\hline \multirow{2}{*}{ Placa corada } & Sem placa/Bom & 30 & $18,2 \%$ & 9 & $15,3 \%$ & 0,611 \\
\hline & Regular/Ruim & 135 & $81,8 \%$ & 50 & $84,7 \%$ & \\
\hline \multirow{2}{*}{$\begin{array}{ll}\text { Crianças } & \text { com } \\
\text { lesões iniciais } & \end{array}$} & Não & 71 & $43,0 \%$ & 19 & $32,2 \%$ & 0,145 \\
\hline & Sim & 94 & $57,0 \%$ & 40 & $67,8 \%$ & \\
\hline \multirow{2}{*}{$\begin{array}{lc}\text { Crianças com } \\
\text { lesões moderadas }\end{array}$} & Não & 60 & $36,4 \%$ & 21 & $35,6 \%$ & 0,916 \\
\hline & Sim & 105 & $63,6 \%$ & 38 & $64,4 \%$ & \\
\hline \multirow{2}{*}{$\begin{array}{l}\text { Crianças com } \\
\text { lesões severas }\end{array}$} & Não & 117 & $70,9 \%$ & 29 & $49,2 \%$ & 0,003 \\
\hline & Sim & 48 & $29,1 \%$ & 30 & $50,8 \%$ & \\
\hline Total & & 165 & & 59 & & \\
\hline
\end{tabular}

Fonte: $\mathrm{O}$ autor 


\subsection{Avaliação das condições clínicas das crianças na avaliação final}

A Tabela 5.3 apresenta as características das crianças avaliadas ao final do estudo após 30 meses de acompanhamento.

Para as avaliações das características clínicas das crianças após 30 meses de acompanhamento, foi levado em consideração a condição da criança na última avaliação de retorno de cada grupo de estudo.

No grupo 1, todas as crianças tiveram melhora das condições clínicas quando comparadas as avaliações iniciais (Al) e a avaliações finais (AF) após 30 meses de estudo. Isso indica que o intervalo de acompanhamento de 4 meses, parece ser efetivo para a diminuição de incidência de cárie.

Tendências semelhantes foram observadas em relação às condições clínicas das crianças do grupo 2. No entanto, pode-se observar que embora tenha ocorrido uma diminuição no número de crianças com lesões de cárie em dentina entre a avaliação inicial (AI0 e final (AF), essa diferença não foi estatisticamente significante.

A última coluna da direita mostra a comparação das características clinicas apresentadas pelas crianças do G1 e G2 ao final do estudo, ou seja, após 30 meses de acompanhamento. Para o desfecho principal incidência de cárie, os dados mostraram que 61 (75\%) crianças do grupo 1 não apresentavam lesões de cárie na última consulta de retorno enquanto que 50 (59,5\%) criançasdo grupo 2 não apresentavam lesões de cárie nessa mesmo momento. Observa-se que há diferença estatística para incidência de cárie entre os grupos de estudo. ( $p=0,033)$. O grupo 1 apresentou mais crianças que finalizaram o estudo sem lesões de cárie, o que permite afirmar que para esse estudo o retorno a cada 4 meses foi mais efetivo em termos de prevenção de lesões de cárie.

Comparando as características clinicas das crianças dos dois grupos entre si no final do estudo (AF) observamos que o G1 apresentou significativamente menos crianças com sangramento gengival ( $p<0,001$ ), menos crianças com placa corada ( $p$ $<0,001)$ e menor número de crianças com lesões moderadas $(p=0,001)$. Frente ao 
exposto, o G1 mostrou-se mais efetivo que o G2 em relação a outras variáveis clinicas relacionadas à prevenção da cárie dental.

Tabela 5.3 - Número de crianças com alto risco de cárie que permaneceram no estudo de acordo com as características clinicas da avaliação inicial (Al) e avaliação final (AF) segundo os intervalos de retorno.

\begin{tabular}{|c|c|c|c|c|c|c|c|c|}
\hline \multirow[b]{3}{*}{ Variável } & \multirow[b]{3}{*}{ Categorização } & \multicolumn{6}{|c|}{ Intervalos de Retorno } & \multirow{3}{*}{$\begin{array}{l}\text { G1 e G2 } \\
\text { AF } \\
p\end{array}$} \\
\hline & & \multicolumn{3}{|c|}{$\begin{array}{l}\text { Grupo 1- } 4 \text { meses } \\
(n=81)\end{array}$} & \multicolumn{3}{|c|}{$\begin{array}{l}\text { Grupo } 2-8 \text { meses } \\
(n=84)\end{array}$} & \\
\hline & & Al & AF & $p$ & $\mathrm{Al}$ & $\mathbf{A F}$ & $\mathbf{P}$ & \\
\hline Placa visível & $\begin{array}{l}\text { Sim } \\
\text { Não }\end{array}$ & $\begin{array}{l}19 \\
62\end{array}$ & $\begin{array}{l}1 \\
80\end{array}$ & $\begin{array}{l}<0,001 \\
\text { df } 1\end{array}$ & $\begin{array}{l}15 \\
69\end{array}$ & $\begin{array}{l}3 \\
81\end{array}$ & $\begin{array}{l}0,003 \\
\text { df } 1\end{array}$ & $\begin{array}{l}0,329 \\
\text { df } 1\end{array}$ \\
\hline Sangramento gengival & $\begin{array}{l}\text { Sim } \\
\text { Não }\end{array}$ & $\begin{array}{l}28 \\
53\end{array}$ & $\begin{array}{l}13 \\
68\end{array}$ & $\begin{array}{l}0,007 \\
\text { df } 1\end{array}$ & $\begin{array}{l}31 \\
53\end{array}$ & $\begin{array}{l}39 \\
45\end{array}$ & $\begin{array}{l}0,210 \\
\text { df } 1\end{array}$ & $\begin{array}{l}<0,001 \\
\text { df } 1\end{array}$ \\
\hline Placa corada & $\begin{array}{l}\text { Regular/Ruim } \\
\text { Sem placa/Bom }\end{array}$ & $\begin{array}{l}65 \\
16\end{array}$ & $\begin{array}{l}16 \\
65\end{array}$ & $\begin{array}{l}<0,001 \\
\text { df } 1\end{array}$ & $\begin{array}{l}70 \\
14\end{array}$ & $\begin{array}{l}57 \\
27\end{array}$ & $\begin{array}{l}0,020 \\
\text { df } 1\end{array}$ & $\begin{array}{l}<0,001 \\
\text { df } 1\end{array}$ \\
\hline $\begin{array}{l}\text { Crianças com lesões } \\
\text { iniciais }\end{array}$ & $\begin{array}{l}0 \\
1 \\
\geq 2\end{array}$ & $\begin{array}{l}33 \\
18 \\
30\end{array}$ & $\begin{array}{l}71 \\
7 \\
3\end{array}$ & $\begin{array}{l}<0,001 \\
\text { df } 2\end{array}$ & $\begin{array}{l}38 \\
16 \\
30\end{array}$ & $\begin{array}{l}75 \\
4 \\
5\end{array}$ & $\begin{array}{l}<0,001 \\
\text { df } 2\end{array}$ & $\begin{array}{l}0,503 \\
\text { df } 2\end{array}$ \\
\hline $\begin{array}{l}\text { Crianças com lesões } \\
\text { moderadas }\end{array}$ & $\begin{array}{l}0 \\
1 \\
>2\end{array}$ & $\begin{array}{l}20 \\
30 \\
31\end{array}$ & $\begin{array}{l}77 \\
3 \\
0\end{array}$ & $\begin{array}{l}<0,001 \\
\text { df } 1\end{array}$ & $\begin{array}{l}40 \\
19 \\
25\end{array}$ & $\begin{array}{l}67 \\
10 \\
7\end{array}$ & $\begin{array}{l}<0,001 \\
\text { df } 2\end{array}$ & $\begin{array}{l}0,001 \\
\text { df } 1\end{array}$ \\
\hline $\begin{array}{l}\text { Crianças com lesões } \\
\text { severas }\end{array}$ & $\begin{array}{l}0 \\
1 \\
>2\end{array}$ & $\begin{array}{l}56 \\
14 \\
11\end{array}$ & $\begin{array}{l}69 \\
8 \\
4\end{array}$ & $\begin{array}{l}0,044 \\
\text { df } 2\end{array}$ & $\begin{array}{l}61 \\
9 \\
14\end{array}$ & $\begin{array}{l}66 \\
6 \\
12\end{array}$ & $\begin{array}{l}0,950 \\
\text { df } 2\end{array}$ & $\begin{array}{l}0,116 \\
\text { df } 2\end{array}$ \\
\hline $\begin{array}{l}\text { Crianças com alguma } \\
\text { lesão de cárie }\end{array}$ & $\begin{array}{l}0 \\
1 \\
>2\end{array}$ & $\begin{array}{l}0 \\
15 \\
66\end{array}$ & $\begin{array}{l}61 \\
10 \\
10\end{array}$ & $\begin{array}{l}<0,001 \\
\text { df } 1\end{array}$ & $\begin{array}{l}0 \\
24 \\
60\end{array}$ & $\begin{array}{l}50 \\
10 \\
24\end{array}$ & $\begin{array}{l}<0,001 \\
\text { df } 1\end{array}$ & $\begin{array}{l}0,033 \\
\text { df } 2\end{array}$ \\
\hline Total & & 81 & 81 & & 84 & 84 & & \\
\hline
\end{tabular}

Fonte: O autor 


\subsection{Ansiedade}

A tabela 5.4 apresenta o número de crianças de acordo com o nível de ansiedade entre as avaliações iniciais (Al) e finais (AF) nos grupos de estudo após 30 meses. É importante ressaltar que não foram observadas respostas em branco na Escala de Imagem Facial (EIF).

Como pode-se observar, para o G1 (4 meses), houve uma melhora estatisticamente significante quando comparada a ansiedade relatada pelas crianças antes da consulta odontológica na avaliação inicial e final. Isso indica que o retorno a cada 4 meses pode deixar as crianças menos ansiosas antes da consulta odontológica.

O G2 (8 meses), também apresentou melhora no número de crianças que relataram estar triste ou muito triste, mas não foi significante $(p=0,102)$.

Após 30 meses de estudo, ao comparar o grau de ansiedade das crianças no final do estudo entre o grupo 1 e o grupo 2 pode-se observar que houve diferença estatística $(p=0,027)$, isso ocorreu porque nenhum paciente do grupo 1 relatou estar triste ou muito triste na última consulta de retorno. 
Tabela 5.4. Número de crianças de acordo com o momento da avaliação e o intervalo de retorno segundo o nível de ansiedade após 30 meses de acompanhamento.

\begin{tabular}{|c|c|c|c|c|c|c|c|c|}
\hline \multirow[b]{3}{*}{ Variável } & \multirow[b]{3}{*}{ Categorização } & \multicolumn{6}{|c|}{ Intervalo de Retorno } & \multirow{3}{*}{$\begin{array}{lll}\text { G1 e } & \text { G2 } \\
\text { AF } & & \\
p & & \end{array}$} \\
\hline & & \multicolumn{3}{|c|}{$\begin{array}{l}\text { Grupo } 1-4 \text { meses } \\
(n=81)\end{array}$} & \multicolumn{3}{|c|}{$\begin{array}{l}\text { Grupo } 2-8 \text { meses } \\
(n=84)\end{array}$} & \\
\hline & & Al & AF & p & Al & AF & $\mathbf{P}$ & \\
\hline Ansiedade & $\begin{array}{l}\text { Muito Feliz/Feliz } \\
\text { Normal } \\
\text { Triste/ Muito Triste }\end{array}$ & $\begin{array}{l}56 \\
12 \\
13\end{array}$ & $\begin{array}{l}78 \\
3 \\
0\end{array}$ & $<0,000$ & $\begin{array}{l}66 \\
6 \\
12\end{array}$ & $\begin{array}{l}72 \\
8 \\
4\end{array}$ & 0,102 & 0,027 \\
\hline Total & & 81 & 81 & & 84 & 84 & & \\
\hline
\end{tabular}

Fonte: O autor 





\section{DISCUSSÃO}

Na literatura odontológica não há evidências suficientes sobre a validade dos diferentes sistemas utilizados para avaliação do risco de cárie em crianças. Além disso, também não há evidências de que o fato de identificar uma criança como sendo de alto risco de cárie, poderia leva-la a um tratamento mais eficaz a longo prazo, que impediria a progressão da doença cárie ${ }^{36}$. O presente estudo é o primeiro ensaio clínico randomizado que avalia a incidência de cárie em dois intervalos de retorno distintos em crianças com alto risco de cárie. Também é o primeiro estudo que compara o nível de ansiedade em diferentes intervalos de retornos dentro de um ensaio clínico randomizado.

Todo estudo foi realizado dentro das unidades escolares, com alunos matrículados nas escolas municipais participantes, sendo assim caracterizado em um contexto de saúde pública. Uma grande contribuição não somente para os clínicos em relação aos intervalos de retornos para crianças com alto risco de cárie, como também para o cenário público.

No início do estudo as caracteristicas clínicas e sociodemográficas, não apresentaram diferença estatística para a maioria dos dados quando comparados os dois grupos $(p>0,05)$, demonstrando assim a homogeneidade entre os grupos, reduzindo vieses inerentes a amostra.

Durante o período do estudo, como esperado em ensaios clínicos randomizados, houve perda amostral. No entanto é importante ressaltar que as proporções entre as crianças perdidas e as que permaneceram em cada grupo de estudo, foram similares levando em consideração cada uma das variáveis analisadas. Mesmo com as perdas amostrais durante 0 estudo, os grupos permaneceram similares como no início do estudo.

O viés devido ao atrito também parece estar sob controle, já que as crianças perdidas no decorrer do estudo $(n=59)$ foram igualmente distribuídas entre os dois grupos, 31 no grupo 1 e 28 no grupo 2. Além disso, mesmo que a amostra perdida tivessem significativamente mais lesões em dentina em comparação com aqueles que permaneceram no estudo, também foram igualmente distribuídos nos dois grupos $(p=0,622)$. 
Este estudo mostrou que os intervalos de retorno clínicos que foram testados para crianças com alto risco de cárie, conseguiram reduzir a quantidade de placa dentária, sangramento gengival e incidência de cárie para ambos os intervalos de retorno utilizados, no entanto 0 intervalo de retorno a cada 4 meses foi significativamente mais efetivo, onde $75 \%$ das crianças pertencentes a esse grupo de estudo, fializaram o estudo sem lesões ativas de cárie, portanto esse intervalo é recomendado.

Segundo dados de uma vigilância epidemiológica, considerado o maior e mais amplo levantamento em saúde bucal já feito no país, mostrou que em 2002 35\% das crianças aos 5 anos de idade possuíam CEOD igual a zero ${ }^{37}$. Esse mesmo levantamento feito em 2010 mostrou que 46,6 \% das crianças aos 5 anos de idade possuíam CEOD igual a zero ${ }^{11}$, mostrando que as medidas públicas preventivas estão auxiliando na melhora da saúde bucal. No presente estudo, em um período de tempo mais curto, $75 \%$ das crianças do grupo 1 finalizaram o estudo sem lesões ativas e $59,5 \%$ do grupo 2 . As medidas de prevenção e orientações de saúde bucal para crianças e seus responsáveis feitas podem auxiliar em ações públicas preventivas em crianças.

Muito embora as características clínicas bucais das crianças tenham melhorado no decorrer do estudo de 30 meses, as crianças foram consideradas como pacientes de alto risco até o final do estudo. Isso porque o fato de todas as crianças terem experiência passada de cárie foi levado em consideração como sendo um critério para determinar o alto risco de cárie e possível desenvolvimento de novas lesões ${ }^{23}$. 


\subsection{Intervalos de retorno e Incidência de cárie}

As análises comparativas para avaliar a incidência de cárie nos intervalos de retorno empregados, foram feitas levando em consideração apenas dois momentos no intervalo de tempo de 30 meses de acompanhamento do estudo. Houve uma avaliação inicial aonde foram consideradas as condições clínicas que cada criança apresentava no início do estudo antes dos tratamentos preventivos e curativos. E a avaliação clinica final foi feita após 30 meses de acompanhamento quando foram coletadas informações das condições clínicas de cada criança. De maneira geral a maioria das crianças apresentaram melhora nas condições clínicas.

Essa melhora também foi observada em um estudo de coorte retrospectivo, que utilizou a mesma ferramenta de avaliação de risco e os mesmos intervalos de retornos. O método de avaliação de risco e as diretrizes de prevenção utilizadas foram eficazes na redução de lesões de cárie ${ }^{18}$, no entanto, as crianças pertenciam ao programa preventivo da Faculdade de Odontologia da Universidade de São Paulo. No presente estudo, as crianças não foram incluídas em um programa e não eram pacientes frequentes da Faculdade de Odontologia, e em ambos os grupos de estudos houve diminuição das lesões de cárie de forma geral.

Mesmo que as crianças dos dois grupos de estudo tenham tido menor incidência de cárie no decorrer do estudo, houve diferença estatística entre os grupos. Crianças que tiveram retorno clinico a cada 4 meses apresentaram significativa redução de incidência de cárie quando comparadas às crianças que tiveram intervalo de retorno a cada 8 meses.

Além disso, crianças que tiveram intervalo de retorno clinico a cada 4 meses também apresentaram significativas melhoras de condições clinicas como diminuição de sangramento gengival, menor quantidade de placa corada e menor incidência de lesões moderadas. De maneira geral, as crianças pré-escolares de alto risco de cárie que tiveram intervalo de retorno clinico de 4 em 4 meses apresentaram melhor condição de saúde bucal em relação as variáveis clínicas relacionadas a prevenção de cárie dental. 
Existem diversas ferramentas que avaliam o risco de cárie dentária, porém poucas associam a avaliação de risco com intervalos de retornos. No método Nexö, por exemplo, o intervalo de retorno para crianças de alto risco é de 1 mês $^{38}$. Este método teve resultados muito bons, pois após um acompanhamento de 18 anos, pode-se observar que o percentual de crianças livre de cárie aumentou de 70\% para 90\% na dentição decídua, ocorreu diminuição de $20 \%$ na incidência de cárie. Talvez o retorno a cada 1 mês não seja viável, pois aumenta o custo do tratamento, aumenta consideravelmente o numero de visitas da criança ao dentista e ainda há crianças que desenvolvem novas lesões de cárie. Quando comparadas as avaliações iniciais com as avaliações finais na tabela 3 para o grupo 1 , houve diferença estatística $(p<0,001)$. Levando em consideração que na avaliação inicial as crianças com lesões de cárie ativa representava $100 \%$ da amostra, o retorno a cada 4 meses apresentou uma redução de $24,7 \%$ na incidência de cárie para crianças classificadas como alto risco de cárie.

O retorno a cada 6 meses é mundialmente utilizado, porém um estudo mostrou que, a aplicação semestral de flúor em crianças, sem a avaliação e a divisão por classificação de risco, não diminui de forma significativa a incidência de cárie na dentição decídua ${ }^{12}$. Com isso é possível inferir que o retorno a cada 4 meses associado com orientações de saúde bucal, como as orientações realizadas nesse estudo, apresentou melhores resultados para pré - escolares com alto risco de cárie, sendo suficiente para diminuir a incidência de cárie nessa população mesmo não realizando aplicação de flúor em todos os retornos.

O intervalo de retorno a cada 3 meses foi proposto pelo método de avalição de risco CAMBRA $^{39}$, mas o efeito desse retorno na incidência de cárie não foi avaliado. Porém não há necessidade de se encurtar o retorno para 3 meses mesmo porque resultados piores foram apresentados quando comparado o retorno a cada 1 mês e a redução da incidência de cárie apresentada pelo retorno a cada 4 meses, com isso, até o momento o retorno a cada 4 meses apresentou melhores resultados em termos de prevenção de incidência de cárie para pré-escolares com alto risco de cárie. 


\subsection{Ansiedade odontológica}

Para o desfecho ansiedade o presente estudo mostrou melhora na ansiedade somente para o grupo de 4 meses quando comparado a avaliação inicial e a avaliação final.

Um estudo anterior relatou que crianças com experiências passadas de cárie, além de demonstrar maior propensão ao desenvolvimento de novas lesões, poderiam apresentar níveis mais elevados de ansiedade na consulta ${ }^{23}$.

No presente estudo todas as crianças possuíam experiência passada de cárie, consequentemente poderiam apresentar níveis mais elevados de ansiedade. No entanto, pode-se observar que quando o intervalo de retorno das consultas odontológicas são mais curtos, por exemplo, a cada 4 meses, além de diminuir a incidência de lesões de cárie, promove menores níveis de ansiedade quando comparado com o retorno a cada 8 meses.

Para ambos os grupos um menor número de crianças relatou estar triste ou muito triste na avaliação final do estudo comparado com a avaliação inicial, sendo esse resultado significativo somente para o grupo de 4 meses. A realização do atendimento no ambiente escolar pode ter sido favorável quando comparado aos atendimentos em consultório, já que as crianças estavam em um ambiente conhecido, a qual frequentam todos os dias. Porém, tanto a avaliação inicial quanto a final foram realizadas no mesmo ambiente, mostrando assim que a melhora não foi devido ao ambiente e está diretamente relacionada com o intervalo de retorno empregado.

O retorno a cada 4 meses apresenta melhores resultados em termos de ansiedade pré consulta odontológica quando comparado com o retorno a cada 8 meses.

Os achados desse estudo além de auxiliar os clínicos em relação as consultas de retornos de crianças com alto risco de cárie, auxilia ações de medidas coletivas para a população, mostrando que é possível reduzir a incidência de cárie em crianças em idades pré escolares de escolas municipais. Sendo as orientações 
de prevenção um fator importante, pois proporciona motivação da promoção de saúde bucal em alunos, pais, professores e diretores. 


\section{CONCLUSÕES}

Os intervalos de retorno a cada 4 meses resultaram em menor incidência de cárie para pré escolares com alto risco de cárie quando comparado ao retorno a cada 8 meses.

Em relação à ansiedade, as crianças pertencentes ao grupo de retorno a cada 4 meses apresentaram menores níveis de ansiedade quando comparadas com as crianças pertencentes ao grupo de retorno a cada 8 meses. 





\section{REFERÊNCIAS 1}

1.Plutzer K, Spencer A. Efficacy of an oral health promotion intervention in the prevention of early childhood caries. Community Dent Oral Epidemiol. 2008 Aug;36 (4):335-46.

2. Nyvad B, Fejerskov O. Assessing the stage of caries lesion activity on the basis of clinical and microbiological examination. Community Dent Oral Epidemiol. 1997 Feb;25(1):69-75.

3.Fejerskov O. Concepts of dental caries and their consequences for understanding the disease. Community Dentistry Oral Epidemiol. 1997 Feb;25(1):5-12.

4. Featherstone JD. The continuum of dental caries--evidence for a dynamic disease process. J Dent Res. 2004;83 Spec No C:C39-42.

5. Silva ACB, Cruz, JS, Sampaio FC, Araújo DAM. Deteç̧ão de estreptococos orais em biofilme dental de crianças cárie-ativas e livres de cárie. Braz Microbiol 2008 dez; 39 (4):648-51

6.Kidd EA, Fejerskov O. What constitutes dental caries? Histopathology of carious enamel and dentin related to the action of cariogenic biofilms. J Dent Res. 2004;83 Spec No C:C35-8

7. Cianetti S, Lombardo G, Lupatelli E, Pagano S, Abraha I, Montedori A, Caruso S, Gatto R, De Giorgio S, Salvato R Dental fear/anxiety among children and adolescents. A systematic review. Eur J Paediatr Dent. 2017 Jun;18(2):121-30. doi: 10.23804/ejpd.2017.18.02.07.

8. Girdler NM, Hill CM, Wilson K. Clinical sedation in dentistry. Chichester: John Wiley \& Sons; 2009.

9. Soares F, Lima R, Barros M, Dahllöf G, Colares V Development of dental anxiety in schoolchildren: A 2-year prospective study. Community Dentistry and Oral Epidemiology. 2017 March; doi.org/10.1111/cdoe.12290

\footnotetext{
${ }^{1}$ De acordo com normas Vancouver
} 
10. Kothari,S; Gurunathan,D Factors influencing anxiety levels in children undergoing dental treatment in an undergraduate clinic. J Family Med Prim Care. 2019 Jun;8(6):2036-2041. doi: 10.4103/jfmpc.jfmpc_229_19.

11. Brasil. Ministério da Saúde. Projeto SB Brasil: Pesquisa Nacional de Saúde Bucal. Brasília (DF): Ministério de Saúde; 2010. Disponível em: [http://189.28.128.100/dab/docs/geral/projeto_sb2010_relatorio_final.pdf.]

12. Oliveira BH, Salazar M, Carvalho DM, Falcão A, Campos K, Nadanovsky P. Biannual fluoride varnish applications and caries incidence in preschoolers: A 24month follow-up randomized placebo-controlled clinical trial. Caries Res. 2014 Jan 29;48(3):228-36 doi 10.1159/000356863

13. Mejàre I, Axelsson S, Dahlén G, Espelid I, Norlund A, Tranæus S, Twetman S. Caries risk assessment. A systematic review. Acta Odontol Scand. 2014;72(2):81-91 doi10.3109/00016357.2013.822548

14. Riley P, Worthington HV, Clarkson JE, Beirne PV. Recall intervals for oral health in primary care patients. Cochrane Database Syst Rev. 2013 Dec 19;12:CD004346.

15. Tellez M, Gomez J, Pretty I, Ellwood R, Ismail A. Evidence on existing caries risk assessment systems: are they predictive of future caries? Community Dent Oral Epidemiol 2013 Feb 41 (1): 67-78. Do10.1111/cdoe12003

16. Christian B, Armstrong R, Calache H, Carpenter L, Gibbs L, Gussy M. A systematic review to assess the methodological quality of studies on measurement properties for caries risk assessment tools for young children. Int J Paediatr Dent. 2019;29:106-16. https://doi.org/10.1111/ipd.12446.

17. Prefeitura da Cidade de São Paulo. Secretaria Municipal da Saúde. Diretrizes para a Atenção em Saúde Bucal - Crescendo e vivendo com saúde bucal. Disponível em: [http://www.prefeitura.sp.gov.br/cidade/secretarias/upload/saude/arquivos/saudebuc al/Diretrizes_Saude_Bucal_2012.pdf]

18. Abanto J, Celiberti P, Braga MM, Vidgal EA, Cordeschi T, Haddad AE, Bonecker $M$. Effectiveness of a prevent program based on caries risk assessment and recall intervals on the incidence and regression of initial caries lesions in children, Int $\mathrm{J}$ Pediatric Dent. 2015,jul;25 (4):291-1. doi:10.1111/ipd12144 
19. Wang NJ, Petersen PE, Sveinsdóttir EG, Arnadóttir IB, Källestål C. Recall intervals and time used for examination and prevention by dentists in child dental care in Denmark, Iceland, Norway and Sweden in 1996 and 2014. Community Dent Health. 2018 Mar 1;35(1):52-57. doi: 10.1922/CDH_4186.

20. Løken SY, Wigen TI, Wang NJ. Recall intervals in children are individualized and extended, Acta Odontol Scand. 2019 aug; 77(6):467-73doi: 10.1080/00016357.2019.1599422.

21. Santos APP, Nadanovsky P, Oliveira BH. A systematic review and meta-analysis of the effects of fluoride toothpastes on the prevention of dental caries in the primary dentition of preschool children. Community Dent Oral Epidemiol. 2013;41(1):1-12. doi:10.1111/j.1600-0528.2012.00708x

22. Dahlander A, Soares F, Grindefjord M, Dahllöf G. Factors Associated with Dental Fear and Anxiety in Children Aged 7 to 9 Years. Dent J (Basel). 2019 Jul 1;7(3). pii: E68. doi: 10.3390/dj7030068.

23. Kothari S, Gurunathan D. Factors influencing anxiety levels in children undergoing dental treatment in an undergraduate clinic. J Family Med Prim Care. 2019 Jun;8(6):2036-2041. doi: 10.4103/jfmpc.jfmpc_229_19.

24. Moher D, Hopewell S, Schulz KF, Montori V, Gøtzsche PC, Devereaux PJ, Elbourne D, Egger M, Altman DG; Consolidated Standards of Reporting Trials Group. CONSORT 2010 Explanation and Elaboration: Updated guidelines for reporting parallel group randomised trials. J Clin Epidemiol. 2010;63:e1-37. doi: 10.1016/j.jclinepi.2010.03.004. Epub 2010 Mar 25. Erratum in: J ClinEpidemiol. 2012;65(3):351

25. Calvert M, Blazeby J, Altman DG, Revicki DA, Moher D, Brundage MD; CONSORT PRO Group. Reporting of patient-reported outcomes in randomized trials: The CONSORT PRO Extension. JAMA 2013 Feb; 309 (8): 814-22. doi:10.1001/jama.2013.879.

26. Petrie A ,Sabin C. Medical statistic at glance. $3^{\text {rd }}$ ed. London:: Wiley Blackwell; 2009.

27. Greene JC, Vermillion JR. The simplified oral hygiene index. J Am Dent Assoc. 1964 Jan;68:7-13.

28. Löe H. The Gingival Index, the Plaque Index and the Retention Index Systems. J. Period. 1967 Nov- Dez; 38 (6): 610-6. 
29. Pitts N. "ICDAS"--an international system for caries detection and assessment being developed to facilitate caries epidemiology, research and appropriate clinical management. Community Dental H. 2004 Sep;21(3):193-8.

30. Buchanan $\mathrm{H}$, Niven $\mathrm{N}$. Validation of a facial image scale to assess child dental anxiety. Int J Paediatr Dent. 2002 jan;12(1):47-52.

31.Guedes-Pinto AC, Issáo M. Manual de odontopediatria. 7. ed. São Paulo: Artes Médicas; 1988.

32. Carvalho JC, Ekstrand KR, Thylstrup A. Results of 1 year of non-operative occlusal caries treatment of erupting permanent first molars. Community Dent Oral Epidemiol. 1991 Feb; 19(1): 23-8.

33. Ekstrand KR1, Qvist V1. The impact of a national caries strategy in Greenland after 4 years. Int J Paediatr Dent. 2015 Jul;25(4):255-66. doi: 10.1111/ipd.12138. Epub 2014 Oct 17.

34. Gao XL, Hsu CY, Xu Y, Hwang HB, Loh T, Koh D. Building caries risk assessment models for children. J Dent Res. 2010 Jun; 89(6):637-43. doi:10.1177/0022034510364489.

35. Ismail Al, Sohn W, Tellez M, Amaya A, Sen A, Hasson H. The International Caries Detection and Assessment System (ICDAS): an integrated system for measuring dental caries. Community Dent Oral Epidemiol. 2007Jun; 35 (3):1708.

36. Petersen PE. World Health Organization global policy for improvement of oral health--World Health Assembly 2007. Int Dent J. 2008 Jun;58 (3):115-21.

37. Brasil. Ministério da Saúde. Projeto SB Brasil: Pesquisa Nacional de Saúde Bucal. Brasília (DF): Ministério de Saúde; 2002. Disponível em: (http:/saude.rs.gov.br/dados/1165252073416h\%20Relat\%F3rio\%20T\%E9cnico \%20da\%20Macrorregi\%E30\%20dos\%20Vales.pdf)

38. Kuzmina,l; Ekstrand,K. Outcomes 18 years after implementation of a nonoperative caries preventive program--the Nexö-method--on children in Moscow, Russia. Community Dent Oral Epidemiol. 2015 Aug;43(4):308-16. doi: 10.1111/cdoe.12155. Epub 2015 Feb 6.23 
39. Ramos-Gomez FJ, Crystal YO, Ng MW, Crall JJ, Featherstone JD. Pediatric dental care: prevention and management protocols based on caries risk assessment. J Calif Dent Assoc. 2010;38(10):746-61. 
APÊNDICE A - Termo de consentimento livre e esclarecido

\section{TERMO DE CONSENTIMENTO LIVRE ESCLARECIDO}

As informações contidas neste documento são fornecidas pelos responsáveis desta pesquisa, Thais Cordeschi e Prof. Dr. Marcelo Bönecker, ambos da Faculdade de Odontologia da Universidade de São Paulo (FOUSP). A presente pesquisa intitulada: "Avaliação de diversos intervalos de retorno associado a orientações de saúde bucal e profilaxia na progressão e incidência de cárie em pacientes com lesões ativas não cavitadas" será realizada na Clínica Odontológica da FOUSP e tem por objetivo avaliar os efeitos benéficos e prejudiciais de diversos intervalos de retornos para consulta, associados a orientações de higiene bucal e profilaxia, na progressão de lesões não cavitadas ativas e incidência de cárie em pré-escolares.

Esta pesquisa será realizada através da execução de exames e procedimentos rotineiros, como exame clínico bucal. Também serão realizados procedimentos como orientação de higiene e dieta e aplicação de dois questionários, um sobre a qualidade de vida relacionada à saúde bucal da criança e outro direcionado à ansiedade odontológica da criança. O tempo despendido será de aproximadamente 30 minutos por sessão para realização de todos os procedimentos descritos, sendo que, o número de sessões de tratamento poderá de variar dependendo do número de dentes que apresentam lesões iniciais de cárie. Será realizado o monitoramento do paciente e dos tratamentos por meio de consultas de acompanhamento clínico (períodos preestabelecidos de 2, 8 meses), onde serão repetidos os exames clínicos bucais e a aplicação dos questionários. Durante o monitoramento será necessário que o responsável (pai, mãe ou responsável legal) que assinar este documento seja o mesmo que traga à criança nas consultas de acompanhamento clínico, sendo que não haverá ressarcimento de despesas de transporte.

Como este estudo se trata de exames odontológicos, como benefício o seu filho (a) receberá informações sobre saúde bucal e tratamento odontológico se necessários tais como obturações até os 12 meses de acompanhamento clínico. Além disso, os resultados do presente estudo trarão maior conhecimento científico sobre o melhor intervalo de retorno determinado para paciente de alto risco. O responsável pelo participante não terá nenhum gasto para a realização dos exames, procedimentos e tratamentos clínicos já que tudo isso será fornecido gratuitamente pelos pesquisadores responsáveis. O responsável pelo participante terá escolha em não participar da pesquisa, tendo a possibilidade de retirar seu consentimento posteriormente, caso mude de opinião por qualquer motivo, sendo que não sofrerá nenhum prejuízo nem penalidade e sem perder os benefícios descritos no parágrafo anterior. Qualquer imprevisto decorrente da pesquisa será de responsabilidade dos pesquisadores, sem prejuízo algum para o participante. Sendo ainda garantida à assistência integral (tratamento odontológico), junto à Disciplina de Odontopediatria da FOUSP, aos pacientes a qualquer momento da pesquisa. Não será revelada, sob nenhuma hipótese, a identidade do participante bem como de seu responsável, sendo que as informações fornecidas serão confidenciais e de conhecimento apenas dos pesquisadores responsáveis. Os sujeitos da pesquisa 
não serão identificados em nenhum momento, mesmo quando os resultados desta pesquisa forem divulgados em qualquer forma.

Os pesquisadores responsáveis estarão à disposição para esclarecer qualquer dúvida e assistência no telefone (11) 3091-7835 e no e-mail: thais.cordeschi@usp.br

Tendo sido descritas todas as informações referentes ao estudo, os pesquisadores responsáveis gostariam de saber se o adulto responsável autoriza a utilização dos dados em outras pesquisas:

( ) NÃO autorizo a utilização de dados em outra pesquisa.

( ) SIM autorizo a utilização de dados em outra pesquisa.

Para utilizar os dados em outra pesquisa o sujeito da pesquisa quer ser consultado:

( ) NÃO quero ser consultado da utilização dos meus dados em outra pesquisa, desde que a nova pesquisa seja aprovado pelo Comitê de Ética em Pesquisa,

( ) SIM quero ser consultado da utilização dos meus dados em outra pesquisa.

Após ter sido informado e ter minhas dúvidas suficientemente esclarecidas pelos pesquisadores, concordo que o meu filho(a): e eu participemos de forma voluntária desta pesquisa. Consto também que recebi uma cópia deste documento assinada pelos pesquisadores. de de 2014.

Assinatura do adulto responsável pelo participante:

Nome por extenso:

$R G$ :

Thais Cordeshi

Pesquisadora - FOUSP

RG: 301282109
Prof. Dr. Marcelo Bönecker

Orientador - FOUSP

RG: 8331127

"Se houver dúvidas sobre a ética da pesquisa entre em contato com o Comitê de Ética em Pesquisa da Faculdade de Odontologia da USP (Av. Lineu Prestes 2227, 05508-000 São Paulo, telefone 30917960 ou pelo e-mail cepfo@usp.br)". 
ANEXO A -. Parecer consubstanciado CEP 1 e 2

Parecer consubstanciado do CEP 1

DADOS DO PROJETO DE PESQUISA

Título da Pesquisa: IMPACTO DE DOIS INTERVALOS DE RETORNO ASSOCIADOS À ORIENTAÇÕES

DE SAÚDE BUCAL NA INCIDÊNCIA DE CÁRIE, ANSIEDADE E QUALIDADE DE

VIDA DE PRÉ-ESCOLARES COM ALTO RISCO DE CÁRIE: ENSAIO CLÍNICO Pesquisador: Thais

Cordeschi Área Temática:

Versão: 1

CAAE: 38138414.7 .0000 .0075

Instituição Proponente: Universidade de São Paulo

Patrocinador Principal: Financiamento Próprio

DADOS DO PARECER

Número do Parecer: 864.405 Data da Relatoria: 09/11/2014

Apresentação do Projeto:

A cárie dentária é uma doença infecciosa, multifatorial de progressão lenta com caráter dinâmico, podendo ser revertida em qualquer momento desde que a relação causa-efeito seja modificada1-2. Quando há desequilíbrio no processo de remineralizarão dentária, pode levar ao desenvolvimento de lesões de cárie ativas ou progressão de lesões já existentes 3-5.

Acredita-se que, caso medidas de educação em saúde bucal e tratamento não operatório das lesões ativas iniciais não sejam adotadas, a tendência será a progressão da lesão até sua cavitação. Porém, em relação à intervenção não operatória, um ensaio clínico randomizado recente em pré-escolares, com diversos níveis de experiência de cárie no baseline, tem mostrado que, a aplicação semestral de flúor verniz em crianças que escovam os dentes com dentifrício fluoretado e que tem acesso à água de abastecimento público fluoretada, não diminui de forma significativa a incidência de cárie na dentição decídua6. Por outro lado, em relação às orientações de saúde bucal, especificamente de higiene, duas revisões sistemáticas recentes tem demonstrado que o uso de dentifrício fluoretado em concentração convencional é efetivo na redução da incidência de cárie na dentição decídua, independentemente do nível de cárie inicial7, assim como em populações com alto risco de cárie.8 A lesão de mancha branca pode inativar devido à presença de flúor constante na saliva em conjunto à desorganização do biofilme dentário pela própria escovação com o

Página 01 de

dentifrício fluoretado1, 7-8.

Um estudo epidemiológico no Brasil, observou uma prevalência de lesões de cárie não cavitadas ativas em torno de $61 \%$ em pré-escolares. 9 Também, o último levantamento epidemiológico a nível nacional, indicou que a prevalência de lesões cavitadas aos 5 anos de idade é de 53,4\%.10 Esta alta prevalência de lesões não cavitadas ativas e cavitadas destaca ainda mais a importância da 
avaliação clínica regular nos retornos às consultas e manejo de fatores relacionados com a doença não permitindo a progressão e sucessiva cavitação das lesões.

A avaliação do risco da doença cárie e a determinação do intervalo de retornos têm sido geralmente realizados pelos clínicos de forma empírica. Em relação à avaliação do risco de cárie, duas revisões sistemáticas que avaliaram diversos sistemas/diretrizes de avaliação do risco, concluíram que a evidência sobre a validade destes sistemas é fraca e limitada, sendo que nenhum sistema apresenta utilidade preditiva de cárie em crianças, principalmente para as de idade pré-escolar11,12. A respeito deste assunto, a Secretaria Municipal da Saúde de São Paulo13, desenvolveu um método de avaliação de risco de cárie, ainda não validado, porém, o mesmo vem sendo utilizado atualmente em todas as crianças da rede de saúde pública do município, apesar da sua subjetividade clínica. Este sistema pode ser considerado como um auxiliar na determinação de grupos de baixo, moderado e alto risco de cárie na população brasileira infantil, e pode ser empregado em pesquisas, desde que adaptado em termos de objetividade na mensuração.

Em relação à determinação de intervalos de retorno, duas revisões sistemáticas concluíram que não há evidencia científica que comprove que o retorno a cada seis meses seja efetivo em termos de prevenção da cárie e custos econômicos em crianças e adultos14,15. Além disso, estas revisões demonstram que há evidência insuficiente procedente para tirar quaisquer conclusões sobre 0 potencial benéfico e prejudicial de alterar o intervalo de retorno entre os controles odontológicos. Assim, atualmente não existe um método cientificamente comprovado para determinar os intervalos de retornos às consultas odontológicas visando à redução da incidência de cárie em populações de alto risco, tais como crianças apresentando lesões ativas e/ou cavitadas em dentina. Desde o enfoque da saúde pública, a relevância deste tipo de estudos permite a correta distribuição e direcionamento dos recursos econômicos para intervalos de retornos que garantam a efetividade na prevenção da doença cárie em crianças, somado a uma melhor Qualidade de Vida Relacionada à Saúde Bucal (QVRSB) de acordo com o ponto de vista da população.

Considerando que cada criança é um indivíduo com condições clínicas e necessidades de tratamento diferentes, isto exige do profissional estratégias de retornos e cuidados preventivos e de tratamento diferenciados com base no risco da doença cárie e da sua atividade. Atualmente é

Página 02 de

de extrema importância conduzir mais ensaios clínicos randomizados bem delineados que proporcionem aos dentistas conclusões mais claras sobre intervalos de retornos adequados para grupos de alto risco de cárie em termos de incidência de cárie, custos, nível de ansiedade e melhora da QVRSB, de acordo com diversos períodos das visitas ao dentista.

Objetivo da Pesquisa:

2.1. Objetivo geral (desfechos primários):

- Avaliar os efeitos benéficos e prejudiciais de dois intervalos de retornos para consulta, associados a orientações de saúde bucal, na incidência de cárie em pré-escolares com alto risco de cárie.

2.2. Objetivos específicos (desfechos secundários)

- Avaliar o nível de ansiedade de pré-escolares de acordo com os diversos intervalos de retorno ao dentista. 
- $\quad$ Avaliar o impacto dos diversos intervalos de retorno na QVRSB de pré-escolares.

- $\quad$ Avaliar a relação entre as condições clínicas, socioeconômicas e de conhecimento sobre saúde bucal iniciais, e a incidência de cárie.

- Avaliar o grau de retenção sobre orientações de higiene bucal em diversos intervalos de retorno.

- Avaliar os custos de atendimento odontológico e tempo na consulta odontológica, bem como os custos de despesas de transporte dos participantes do estudo, de acordo com os intervalos de retorno ao dentista.

Avaliação dos Riscos e Benefícios:

RISCOS - São mínimos, pois são relativos ao atendimento básico de rotina em Odontopediatria.

Benefícios - os participantes vão receber informações sobre saúde bucal e tratamento odontológico se necessário tais como obturações até os 12 meses de acompanhamento clínico. Além disso, os resultados do presente estudo trarão maior conhecimento científico sobre o melhor intervalo de retorno determinado para paciente de alto risco.

Comentários e Considerações sobre a Pesquisa:

A pesquisa é relevante, pois planeja obter evidências sobre qual o intervalo mais adequado para retorno do paciente pediátrico ao consultório odontológico.

Considerações sobre os Termos de apresentação obrigatória:

Folha de Rosto - OK

TCLE - OK

Autorização clínica - OK

Página 03 de

Resp. Instituição - OK

Projeto - OK

Recomendações:

Tendo em vista a legislação vigente, devem ser encaminhados ao CEP-FOUSP relatórios parciais anuais referentes ao andamento da pesquisa e relatório final ao termino do trabalho. Qualquer modificação do projeto original deve ser apresentada a este CEP, de forma objetiva e com justificativas, para nova apreciação.

Conclusões ou Pendências e Lista de Inadequações:

Não há.

Situação do Parecer:

Aprovado

Necessita Apreciação da CONEP:

Não

Considerações Finais a critério do CEP:

SAO PAULO, 10 de Novembro de 2014.

Assinado por:

Maria Gabriela HayeBiazevic 
(Coordenador)

Parecer consubstanciado do CEP 2

DADOS DO PROJETO DE PESQUISA

Título da Pesquisa: IMPACTO DE DOIS INTERVALOS DE RETORNO ASSOCIADOS À ORIENTAÇÕES

DE SAÚDE BUCAL NA INCIDÊNCIA DE CÁRIE, ANSIEDADE E QUALIDADE DE VIDA DE PRÉ-ESCOLARES COM ALTO RISCO DE CÁRIE: ENSAIO CLÍNICO

Pesquisador: Thais Cordeschi Área Temática:

Versão: 2

CAAE: 38138414.7 .0000 .0075

Instituição Proponente:Universidade de Sao Paulo

Patrocinador Principal: Financiamento Próprio

DADOS DO PARECER

Número do Parecer: 1.121 .868

Data da Relatoria: 24/06/2015

Apresentação do Projeto:

A carie dentaria e uma doença infecciosa, multifatorial de progressão lenta com caráter dinâmico, podendo ser revertida em qualquer momento desde que a relação causa-efeito seja modificada1-2. Quando há desequilíbrio no processo de remineralizarão dentaria, pode levar ao desenvolvimento de lesões de carie ativas ou progressão de lesões existentes 3-5.

Acredita-se que, caso medidas de educação em saúde bucal e tratamento não operatório das lesões ativas iniciais não sejam adotadas, a tendência será a progressão da lesão ate sua cavitação. Porém, em relação à intervenção não operatória, um ensaio clinico randomizado recente em pré-escolares, com diversos níveis de experiência de carie no baseline, tem mostrado que, a aplicação semestral de flúor verniz em crianças que escovam os dentes com dentifrício fluoretado e que tem acesso a agua de abastecimento público fluoretada, não diminui de forma significativa a incidência de carie na 
dentição decidua6. Por outro lado, em relação às orientações de saúde bucal, especificamente de higiene, duas revisões sistemáticas recentes tem demonstrado que o uso de dentifrício fluoretado em concentração convencional e efetivo na redução da incidência de carie na dentição decídua, independentemente do nível de carie inicial7, assim como em populações com alto risco de carie.8 A lesão de mancha branca pode inativar devido à presença de flúor constante na saliva em conjunto a desorganização do biofilme dentário pela própria escovação com o dentifrício fluoretado1, 7-8. Um estudo epidemiológico no Brasil, observou uma prevalência de lesões de carie não cavitadas ativas em torno de $61 \%$ em pre-escolares.9 Também, o ultimo levantamento epidemiológico a nível nacional, indicou que a prevalência de lesões cavitadas aos 5 anos de idade e de 53,4\%.10 Esta alta prevalência de lesões não cavitadas ativas e cavitadas destaca ainda mais a importância da avaliação clinica regular nos retornos as consultas e manejo de fatores relacionados com a doença não permitindo a progressão e sucessiva cavitação das lesões. A avaliação do risco da doença carie e a determinação do intervalo de retornos tem sido geralmente realizados pelos clínicos de forma empírica. Em relação à avaliação do risco de carie, duas revisões sistemáticas que avaliaram diversos sistemas/diretrizes de avaliação do risco, concluíram que a evidencia sobre a validade destes sistemas e fraca e limitada, sendo que nenhum sistema apresenta utilidade preditiva de carie em crianças, principalmente para as de idade pre-escolar11,12. A respeito deste assunto, a Secretaria Municipal da Saúde de São Paulo13, desenvolveu um método de avaliação de risco de carie, ainda não validado, porém, o mesmo vem sendo utilizado atualmente em todas as crianças da rede de saúde publica do município, apesar da sua subjetividade clinica. Este sistema pode ser considerado como um auxiliar na determinação de grupos de baixo, moderado e alto risco de carie na população brasileira infantil, e pode ser empregado em pesquisas, desde que adaptado em termos de objetividade na mensuração. Em relação à determinação de intervalos de retorno, duas revisões sistemáticas concluíram que não há evidência científica que comprove que o retorno a cada seis meses seja efetivo em termos de prevenção da carie e custos econômicos em crianças e adultos 14 , 15. Além disso, estas revisões demonstram que ha evidencia insuficiente procedente para tirar quaisquer conclusões sobre o potencial benéfico e prejudicial de alterar o intervalo de retorno entre os controles odontológicos. Assim, atualmente não existe um método cientificamente comprovado para determinar os intervalos de retornos às consultas odontológicas visando à redução da incidência de carie em populações de alto risco, tais como crianças apresentando lesões ativas e/ou cavitadas em dentina. Desde o enfoque da saúde publica, a relevância deste tipo de estudos permite a correta distribuição e direcionamento dos recursos econômicos para intervalos de retornos que garantam a efetividade na prevenção da doença carie em crianças, somado a uma melhor Qualidade de Vida Relacionada à Saúde Bucal (QVRSB) de acordo com o ponto de vista da população. Considerando que cada criança e um individuo com condições clinicas e necessidades de tratamento diferentes, isto exige do profissional estratégias de retornos e cuidados preventivos e de tratamento diferenciados com base no risco da doença carie e da sua atividade. Atualmente e de extrema importância conduzir mais ensaios clínicos randomizados bem delineados que proporcionem aos dentistas conclusões mais claras sobre intervalos de retornos adequados para grupos de alto risco de carie em termos de 
incidência de carie, custos, nível de ansiedade e melhora da QVRSB, de acordo com diversos períodos das visitas ao dentista.

Objetivo da Pesquisa:

2.1. Objetivo geral (desfechos primários):

Avaliar os efeitos benéficos e prejudiciais de dois intervalos de retornos para consulta, associados a orientações de saúde bucal, na incidência de carie em pré-escolares com alto risco de carie. 2.2.Objetivos específicos (desfechos secundários)

Avaliar o nível de ansiedade de pré-escolares de acordo com os diversos intervalos de retorno ao dentista.

- $\quad$ Avaliar o impacto dos diversos intervalos de retorno na QVRSB de pré-escolares.

- Avaliar a relação entre as condições clinicas socioeconômicas e de conhecimento sobre saúde bucal iniciais, e a incidência de carie.

Avaliar o grau de retenção sobre orientações de higiene bucal em diversos intervalos de retorno.

Avaliar os custos de atendimento odontológico e tempo na consulta odontológica, bem como os custos de despesas de transporte dos participantes do estudo, de acordo com os intervalos de retorno ao dentista.

Avaliação dos Riscos e Benefícios:

RISCOS - São mínimos, pois são relativos ao atendimento básico de rotina em Odontopediatria.

Beneficios - os participantes vão receber informações sobre saúde bucal e tratamento odontológico se necessário tais como obturações até os 12 meses de acompanhamento clinico. Além disso, os resultados do presente estudo trarão maior conhecimento cientifico sobre o melhor intervalo de retorno determinado para paciente de alto risco.

Comentários e Considerações sobre a Pesquisa:

A pesquisa e relevante, pois planeja obter evidencias sobre qual o intervalo mais adequado para retorno do paciente pediátrico ao consultório odontológico.

Considerações sobre os Termos de apresentação obrigatória:

Justifivativa emenda - Ok

Folha de Rosto - OK

TCLE - OK

Autorização clinica - OK

Recomendações:

Tendo em vista a legislação vigente, devem ser encaminhados ao CEP-FOUSP relatórios parciais anuais referentes ao andamento da pesquisa e relatório final, utilizando-se da opção "Enviar 
Notificação" (descrita no Manual "Submeter Notificação", disponível na Central de Suporte - canto superior direito do site www.saude.gov.br/plataformabrasil).

Qualquer alteração no projeto original deve ser apresentada "emenda" a este CEP, de forma objetiva e com justificativas para nova apreciação.

Conclusões ou Pendências e Lista de Inadequações:

Não há pendências.

Situação do Parecer:

Aprovado

Necessita Apreciação da CONEP:

Não

Considerações Finais a critério do CEP:

SAO PAULO, 24 de Junho de 2015.

Assinado por:

Décio dos Santos Pinto Junior

(Coordenador) 


ANEXO B - Registro no Clinical Trials

ClinicalTrials.gov Protocol and Results Registration System (PRS) Receipt

Release Date: 08/31/2015

Impact of Two Recall Intervals on Dental Caries

Incidence and Other Outcomes of Preschool Children

This study is ongoing, but not recruiting participants.

Sponsor: UniversityofSao Paulo

Collaborators:

Information provided by (Responsible Party): Thais Cordeschi, University of Sao Paulo

ClinicalTrials.gov Identifier: NCT02537184

Purpose

Objectives: To assess the beneficial and harmful effects of two recall intervals on caries incidence (primary outcome) in preschool children with high caries risk. The level of anxiety, oral health related quality of life (OHRQoL), time and cost (secondary outcomes) according to each interval will also be assessed. Methods: The sample will consist of 224 children between 3-5 years of age, of both genders, with high caries risk according to the clinical criteria adapted from the Municipal Health Secretary of São Paulo. Children will be randomly allocated into two study groups: Group 1 (G1) - oral clinical examination + orientation for oral health and diet in return for 4 months; and Group 2 (G2) oral clinical examination + orientation for oral health and diet in return for 8 months. An examiner calibrated and blinded to the study groups and the secondary outcomes will perform the clinical examinations, which consist of: gingival bleeding index, dental plaque index, detection of caries and its activity according to the ICDAS (International Caries Detection and Assessment System) and LAA (Lesion Activity Assessment), respectively. An external dentist will conduct the assessment of the anxiety levels assessed by the Facial Image Scale, the OHRQoL measured by B-ECOHIS, the time and costs. All groups will be followed for an initial period of 16 months, totaling four follow-up visits for G1 and two follow-up visits to the G2. All analyzes will be performed by intention to treat (ITT) and considering the sensitivity analysis to assess the differences between the ITT analyzes and analyzes of complete cases.

Condition Intervention Phase

Dental Caries

Quality of Life

Anxiety Procedure/Surgery: Oral Clinical conditions N/A

StudyType: Interventional

Study Design: Prevention, Parallel Assignment, Single Blind (Investigator), Randomized 
Official Title: Impact of Two Recall Intervals Associated to Oral Health Counseling on Dental Caries Incidence, Anxiety and Quality of Life of Preschool Children With High Caries Risk: Randomized Clinical Trial

Further study details as provided by Thais Cordeschi, University of Sao Paulo:

PrimaryOutcomeMeasure:

- Dental caries incidence [Time Frame: Baseline, 4 months and 8 months] [Designated as safety issue: Yes]

Dental caries will be assessed using the ICDAS criteria (Ismail AI, Sohn W, Tellez M, Amaya A, Sen A, Hasson $\mathrm{H}$, et al. The International Caries Detection and Assessment System (ICDAS): an integrated system for measuring dental caries. CommunityDent Oral Epidemiol 2007; 35: 170-8). SecondaryOutcomeMeasures:

- Level of anxiety [Time Frame: Baseline, 4 months and 8 months] [Designated as safety issue: Yes] Level of anxiety will be assessed using the Facial Image Scale (Buchanan H, Niven N. Validation of a facial image scale to assess child dental anxiety. Int J PaediatrDent2002;12:47-52)

- Oral health related quality of life [Time Frame: Baseline, 4 months and 8 months] [Designated as safety issue: Yes]

Oral health related quality of life will be assessed using the Brazilian validation of the ECOHIS (Scarpelli AC, Oliveira BH, Tesch FC, Leão AT, Pordeus IA, Paiva SM. Psychometric properties of the Brazilian version of the Early Childhood Oral Health Impact Scale (B-ECOHIS). BMC Oral Health. $2011 ; 11: 19)$.

- Time [Time Frame: Baseline, 4 months and 8 months] [Designated as safety issue: Yes] The time in minutes, used in the recall interval visits, will be recorded in four categories: time spent on clinical examination including prophylaxis, hygiene and diet orientations, and time spent when the patient miss the recall visit. The total time will correspond to the sum of these categories.

- Costs [Time Frame: Baseline, 4 months and 8 months] [Designated as safety issue: Yes]

Costs in real (continuous variable) will be recorded in three categories: salary of the dentist and dental assistant paid in public dental services in São Paulo, cost of dental materials/products used in the appointment.

Estimated Enrollment: 224

Study Start Date: September 2014

Estimated Primary Completion Date: August 2016

Estimated Study Completion Date: August 2016

Arms Assignedlnterventions

Group 1 - Recall Interval of 4 months Oral clinical conditions:

Only at baseline all childrens will receive

$5 \%$ sodium FV (Duraphat, Colgate Oral Pharmaceuticals). Caries incidence assessment dental anxiety assessment oral health related quality of life

assessment time and costs assessment Procedure/Surgery: Oral clinical conditions Caries incidence assessment dental anxiety assessment oral health related quality of life assessment time and costs 
assessment Procedure/Surgery: Oral Clinical conditions caries incidence assessment dental anxiety assessment

Other Names: Caries Incidence dental anxiety

oral health related quality of life time and costs

Group 2 - Recall Interval of 8 months Oral clinical conditions:

Only at baseline all childrens will receive

$5 \%$ sodium FV (Duraphat, Colgate Oral Pharmaceuticals). Caries incidence assessment dental anxiety assessment oral health related quality of life

assessment time and costs assessment Procedure/Surgery: Oral clinical conditions Caries incidence assessment dental anxiety assessment oral health related quality of life assessment time and costs assessment Procedure/Surgery: Oral Clinical conditions caries incidence assessment dental anxiety assessment

Other Names: Caries Incidence dental anxiety

oral health related quality of life time and costs

Detailed Description:

An examiner calibrated and blinded to the study groups and the secondary outcomes will perform the clinical examinations, which consist of: the gingival bleeding index, dental plaque index, detection of caries and its activity according to the ICDAS (International Caries Detection and Assessment System) and LAA (Lesion Activity Assessment), respectively. An external dentist will conduct the assessment of the anxiety levels assessed by the Facial Image Scale, the OHRQoL measured by B-ECOHIS (Brazilian Early Childhood Oral Health Impact Scale), the time and costs. All groups will be followed for a period of 36 months. All analyzes will be performed with the intention of treatment (ITT) and considering the sensitivity analyzes to assess the differences between the ITT analyzes and the complete cases analyzes.

Eligibility

Ages Eligible for Study: 3 Years to 5 Years

Genders Eligible for Study: Both

Accepts Healthy Volunteers: Yes

Criteria

- InclusionCriteria:

- InclusionCriteria:

- Children between 3-5 years of age, of both genders, with caries high risk according to the clinical criteria adapted from the Secretary of Health of São Paulo and enrolled in public schools.

- Guardians who have signed the informed consent confirming their participation and their child in research.

ExclusionCriteria:

- Children showing visible dental plaque and gingivitis in baseline.

- Children showing more than 06 active and/or inactive caries cavitated surfaces, and who show fistula and/or dental abscess.

- Specialpatients. 
- Children who received professional application of fluoride in the 6 months prior to the Contacts and Locations

Locations

Brazil

Dental School of University of São Paulo São Paulo, São Paulo, Brazil, 05508-000 Investigators

Study Chair: Marcelo Bonecker, Professor University of São Paulo More Information

Responsible Party: Thais Cordeschi, MSc student, University of Sao Paulo

Study ID Numbers: 2014/17758-6

Health Authority: Brazil: National Committee of Ethics in Research

U.S. National Library of Medicine | U.S. National Institutes of Health | U.S. Department of Health \& Human Services 
ANEXO C - ICDAS

ICDAS e Critérios para atividade das lesões de cárie

Escore Critérios de classificação

0

Nenhuma ou sutil alteração na translucidez do esmalte após secagem prolongada (5s)

Opacidade dificilmente visível na superfície úmida, mas notável após secagem

Opacidade visível sem secagem

Cavitação localizada em esmalte opaco ou pigmentado

Sombreamento da dentina subjacente

Cavitação em esmalte opaco ou pigmentado com exposição da dentina subjacente

Cavitação em esmalte opaco ou pigmentado com exposição da dentina subjacente, envolvendo mais de metade da superfície.

\section{Critério de Avaliação da atividade de cárie}

\begin{tabular}{|c|c|c|}
\hline $\begin{array}{l}\text { Código do } \\
\text { ICDAS }\end{array}$ & Lesão Ativa (a) & Lesão inativa (i) \\
\hline 1,2 ou 3 & $\begin{array}{l}\text { Esmalte com opacidade esbranquiçada ou } \\
\text { amarelada, perda de brilho, que parece } \\
\text { rugoso ao se passar a sonda suavemente } \\
\text { sobre a superfície. Lesão localizada em } \\
\text { região com estagnação de placa (fossas e } \\
\text { fissuras, perto da margem gengival, } \\
\text { superfícies proximais abaixo do ponto de } \\
\text { contato }\end{array}$ & $\begin{array}{l}\text { Esmalte esbranquiçado, } \\
\text { amarronzado ou enegrecido, com } \\
\text { aspecto brilhante, duro e liso } \\
\text { quando se passa a sonda } \\
\text { suavemente sobre a superfície. } \\
\text { Para superfícies lisas, essas lesões } \\
\text { tipicamente estão distantes da } \\
\text { margem gengival. }\end{array}$ \\
\hline 4 & Provavelmente ativa & \\
\hline $\begin{array}{l}5 \\
\text { ou } \\
6\end{array}$ & $\begin{array}{l}\text { Cavidade mostrando ao fundo tecido } \\
\text { amolecido ao se passar a sonda. }\end{array}$ & $\begin{array}{l}\text { Cavidade mostrando ao fundo } \\
\text { tecido endurecido ao se passar a } \\
\text { sonda, além de aspecto brilhante } \\
\text { (sem opacidades). }\end{array}$ \\
\hline
\end{tabular}





ANEXO D - Índice de Greene e Vermillion simplificado

\begin{tabular}{|l|l|}
\hline Escore & Condição \\
\hline 0 & Sem placa \\
\hline 1 & $1 / 3$ da superfície corada \\
\hline 2 & $\begin{array}{l}\text { De } 1 / 3 \text { a } 2 / 3 \text { da superfície } \\
\text { corada }\end{array}$ \\
\hline 3 & $\begin{array}{l}\text { Mais de 2/3 da superfície } \\
\text { corada }\end{array}$ \\
\hline
\end{tabular}





ANEXO E - Índice de sangramento gengival de Löe

\begin{tabular}{|c|c|}
\hline Escore & Sangramento \\
\hline 0 & Sem sangramento \\
\hline 1 & Edema \\
\hline 2 & Sangramento à sondagem \\
\hline 3 & $\begin{array}{c}\text { Sangramento espontâneo (com } \\
\text { seringa de ar) }\end{array}$ \\
\hline
\end{tabular}





ANEXO F - Escala de imagem Facial

Pedir para a criança apontar a carinha que mais demonstra como ela está se sentindo agora:
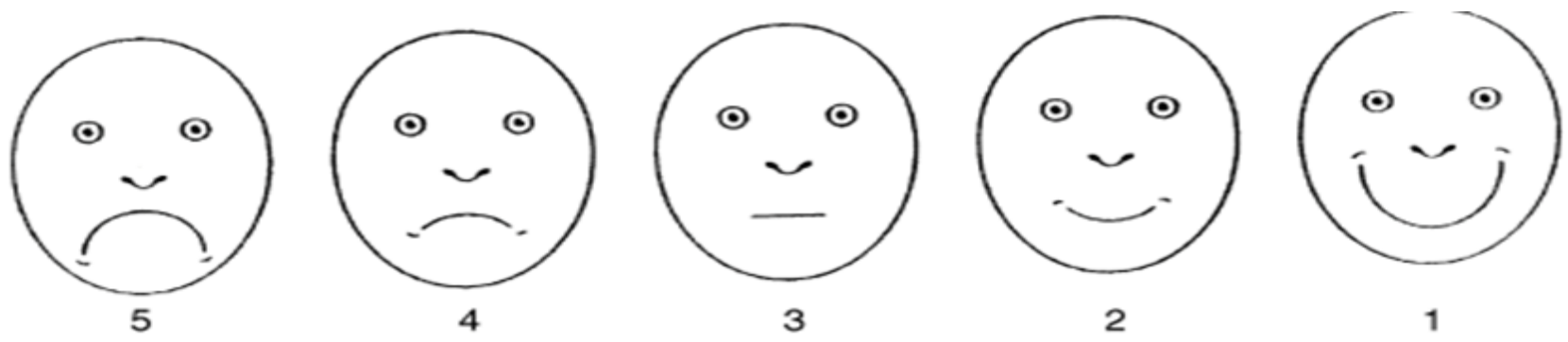